\title{
How does successive inpatriation contribute to subsidiary capability building and subsidiary evolution? An organizational knowledge creation perspective
}

Heejin Kim ${ }^{1}$, B. Sebastian Reiche ${ }^{2}$ and Anne-Wil Harzing ${ }^{3,4}$

${ }^{1}$ Graduate School of Economics and Management, Tohoku University, 27-1, Kawauchi, Aoba-ku, Sendai 980-8576, Japan;

${ }^{2}$ Department of Managing People in Organizations, IESE Business School, Ave. Pearson 21, 08034 Barcelona, Spain; ${ }^{3}$ Business School, Middlesex University London, The Burroughs, London NW4 4BT, UK; ${ }^{4}$ Department of Public Governance, Tilburg University, Tilburg,

The Netherlands

Correspondence:

H Kim, Graduate School of Economics and Management, Tohoku University, 27-1,

Kawauchi, Aoba-ku, Sendai 980-8576, Japan e-mail: kim@tohoku.ac.jp

\begin{abstract}
Intra-company knowledge transfer is a key source of competitive advantage for multinational companies (MNCs) and this knowledge is usually embedded in individuals. Drawing on organizational knowledge creation theory, we explore how inpatriation contributes to knowledge transfer and, in turn, subsidiary performance. Inpatriation involves the international assignment of employees from an MNC's foreign subsidiary to its headquarters. Despite increasing attention to the role of inpatriation, we lack a clear understanding of whether and how inpatriates provide value to their subsidiaries after returning from headquarters. Through a qualitative case study of Japanese MNCs, we demonstrate the process through which inpatriates' knowledge transfer contributes to subsidiary capability building and subsidiary evolution over time, and explain why successive inpatriation is thus critical to enhance subsidiary performance. Our theoretical model highlights the value of inpatriates as knowledge agents, reveals the process through which inpatriates transfer knowledge between $\mathrm{HQ}$ and subsidiaries, and provides a more nuanced understanding of the micro-foundations of intra-MNC knowledge transfer processes. Based on these findings, we argue that inpatriation is not merely a staffing method that is complementary to expatriation, but a key practice in its own right to support subsidiaries' growth and performance.

Journal of International Business Studies (2022) 53, 1394-1419. https://doi.org/ | 0.1057/s4 I 267-02 I-00494-3
\end{abstract}

Keywords: organizational knowledge creation theory; inpatriation; knowledge transfer process; subsidiary performance; Japanese MNCs

The online version of this article is available Open Access

\section{INTRODUCTION}

Received: 13 September 2020

Revised: 28 July 2021

Accepted: 15 November 2021

Online publication date: 12 January 2022
Intra-company knowledge transfer has long been acknowledged as a key source of competitive advantage for multinational companies (MNCs) (Bartlett \& Ghoshal, 1989; Gupta \& Govindarajan, 2000; 
Kogut \& Zander, 1993), and this knowledge is usually embedded in individuals (Argote, 1999; Nonaka, 1994). Thus, 'mobility of individuals' is a powerful mechanism for facilitating knowledge transfer in MNCs. Traditionally, expatriation has featured prominently in this discussion (Caligiuri \& Bonache, 2016; Harzing, 2001). More recently, as scholars have turned their attention to the diversification of global work arrangements (Collings, 2014; Collings \& Isichei, 2017; Reiche, Lee, \& Allen, 2019), inpatriation has received increasing attention (e.g., Duvivier, Peeters, \& Harzing, 2019; Harzing, Pudelko, \& Reiche, 2016). An "inpatriate" is defined as an employee who is transferred from an MNC subsidiary to the corporation's headquarters (HQ) for a limited period of time (Harvey \& Buckley, 1997). After Reiche $(2006,2011)$ first demonstrated inpatriates' role in knowledge transfer, recent research has provided some evidence that inpatriation is a complementary or possibly even superior means of knowledge transfer between subsidiaries and HQ (Duvivier et al., 2019; Harzing et al., 2016). However, we know little about the process and strategic outcomes of inpatriates' knowledge transfer after returning from their assignment at HQ.

Our central research question therefore explores whether and how inpatriates' knowledge transfer activities provide value to their subsidiary. Drawing on insights from organizational knowledge creation theory (Nonaka, 1994), our study investigates how inpatriates transfer knowledge and contribute to subsidiary capability building and subsidiary evolution (Birkinshaw \& Hood, 1998; Gupta \& Govindarajan, 2000; Luo, 2002). We define subsidiary capability building as developing a subsidiary's distinctive resources and unique skills through learning from other organizations (in this case HQ) and creating new business opportunities. In turn, subsidiary evolution is the consequence of a subsidiary's accumulated capabilities, resulting in a change in the roles and responsibilities of a subsidiary in the differentiated MNC network (Birkinshaw \& Hood, 1998; Luo, 2002). By linking inpatriates' knowledge transfer to these two performance-related outcomes, we respond to calls for more empirical work that substantiates inpatriation as a source of strategic value to MNCs (Moeller \& Reiche, 2017).

To generate rich data and insights, we opted for a qualitative research strategy (Patton, 2002). Our case study approach is an especially suitable method, as it enables unique insights into how certain conditions change over time and move towards a certain outcome (Pettigrew, 1990; Soulsby \& Clark, 2011). Further, to extend the geographical base of inpatriation research beyond its traditional focus on Western countries (for reviews see Moeller \& Reiche, 2017; Moeller \& Harvey, 2018), we chose Japanese MNCs operating in Asia as our research context in line with recent empirical studies in the Asian region (e.g., Sarabi, Froese, \& Hamori, 2017). Our data, derived from 40 interviews in Japanese MNCs' HQs and their overseas subsidiaries as well as three forms of timestamped archival data, illuminate the short- and long-term functions of inpatriation that contribute to subsidiary capability building and subsidiary evolution.

In line with recent calls for further research into the strategic value of international human resource management (IHRM) more broadly (e.g., Andersson, Brewster, Minbaeva, Narula, \& Wood, 2019; McNulty \& Brewster, 2017), our study bridges and contributes to both the IHRM and the global strategy literature. Our findings disentangle the explanatory mechanisms through which shortterm functions of inpatriation (the acquisition of task knowledge, language/cultural knowledge, and relational knowledge) develop into long-term functions (building subsidiary absorptive capability, and maintaining access to information), which in turn result in subsidiary capability building and subsidiary evolution. In doing so, we derive a theoretical model that highlights why successive and long-term inpatriation is critical in this process.

We advance research in three distinct areas that emphasize different stages of this model. First, our empirical evidence shows how the individual tacit knowledge that inpatriates acquired at HQ is converted into organizational knowledge upon their return to their original subsidiaries. Specifically, we demonstrate how organizational knowledge creation theory (Nonaka, 1994) can be expanded to the MNC context, and how this theory could serve as a fruitful lens to further investigate the dynamic link between IHRM and the performance-related outcomes of knowledge transfer. Second, we extend existing work on inpatriates' knowledge transfer role (Duvivier et al., 2019; Harzing et al., 2016; Reiche, 2011) by identifying how inpatriates' knowledge transfer provides strategic value to subsidiaries in the form of the performance-related outcomes of subsidiary capabilities and subsidiary evolution. Third, our study contributes to the 
global strategy literature by suggesting that the successive use of inpatriation serves as an effective process for subsidiary evolution. In particular, we provide a deeper understanding of how a subsidiary, as a result of an increasing number of returning inpatriates over time, transforms itself from a passive recipient of $\mathrm{HQ}$ knowledge to an active contributor to the MNC network. This is in line with global strategy scholars' recent focus on examining the micro-foundations of firm-level concepts, including knowledge transfer (Contractor, Foss, Kundu, \& Lahiri, 2019; Foss \& Pedersen, 2019; Tippmann, Scott, \& Mangematin, 2014).

The remainder of this article is structured as follows. First, we review the literature on organizational knowledge creation, inpatriates' knowledge transfer, subsidiary capability building, and subsidiary evolution. Then, we provide a detailed account of our qualitative research design, the three phases of data collection, and the data analysis based on our 'temporal bracketing strategy'. Subsequently, we present the findings through which we build our theoretical model. We conclude with the theoretical and managerial implications of our study and suggest three directions for further research.

\section{THEORETICAL BACKGROUND}

\section{Organizational Knowledge Creation}

Individuals, as the principal repositories of knowledge, are primary actors in knowledge creation and knowledge transfer (Grant, 1996; Kogut \& Zander, 1992). Knowledge transfer is commonly defined as the activities and processes by which knowledge is deliberately moved across different units within an organization (intra-firm) or across organizational boundaries (inter-firm) (Argote, 1999). How to successfully transfer tacit knowledge that is rare, valuable, and difficult to imitate has been a central theme in both international business and global strategy research (Kogut \& Zander, 1992; Michailova \& Mustaffa, 2012). Because tacit knowledge is best transferred through direct social interactions (Nonaka \& Takeuchi, 1995), the mobility of individuals is generally seen as a powerful mechanism for facilitating knowledge transfer in organizations.

Organizational knowledge creation theory (OKCT) (Nonaka, 1994) serves as a fruitful lens to understand the dynamic human process that transcends existing boundaries in order to transfer and create knowledge in organizations. In this theory, organizational knowledge creation is defined as "the capability of a company as a whole to create new knowledge, disseminate it throughout the organization, and embody it in products, services, and systems" (Nonaka \& Takeuchi, 1995, p. 58). A key concept in Nonaka's theory is knowledge conversion which is based on how two types of knowledge (tacit and explicit) interact to create new organizational knowledge. In his SECI model, Nonaka suggests four modes of knowledge conversion: (1) tacit to tacit (socialization), (2) tacit to explicit (externalization), (3) explicit to explicit (combination), and (4) explicit to tacit (internalization). He emphasizes that tacit knowledge embedded in individuals may lie at the heart of the knowledge creating process, and that it is mobilized through dynamic interactions between all four modes of knowledge conversion. Given that tacit knowledge can only be transferred through personal interactions, the effective design of global staffing practices is crucial in facilitating MNC knowledge flows (Michailova \& Mustaffa, 2012).

MNCs' level of heterogeneity and complexity, including their external environment, intra-organizational diversity, and individual variability are a useful context for theory extension (Roth \& Kostova, 2003), in our case of OKCT. MNCs' global expansion can be understood as a chain of knowledge creation in diverse foreign contexts, and thus the raison d'être of an MNC is to continuously create knowledge across borders. In a further elaboration of the theory, Nonaka, Toyama and Konno (2000) propose a model of knowledge creation consisting of three elements: (1) the SECI process, (2) ' $b a$ ', the shared context for knowledge creation, and (3) knowledge assets, the firm-specific resources that are indispensable to create value for the firm. In the MNC context, using existing 'knowledge assets' of the HQ, an MNC can continuously create new knowledge through the 'SECI process' that takes place in ' $b a$ ', i.e., the home and various host country contexts. Nonaka et al. (2000) emphasize that knowledge is created through the interactions amongst individuals or between individuals and their environment, for which ' $b a$ ' works as a shared context or platform. Thus, MNC subsidiaries' social, cultural, and historical contexts are important for the individuals engaged in knowledge creation. As such, context provides the basis for the interpretation of information (knowledge assets in HQ) to create meaning (performance in a local market). The core concepts and logics of OKCT thus offer a useful lens to understand how 
inpatriates engage in dynamic interactions through the SECI process, resulting in the creation of value for subsidiaries and the MNC as a whole.

\section{Inpatriates as Knowledge Agents}

IHRM research has developed an understanding of the micro-level variables related to the cross-national transfer of management practices (De Cieri \& Dowling, 2012). Home-country expatriates have been shown to be an important mechanism of managerial and technological knowledge transfer from MNC HQs to foreign subsidiaries (Caligiuri \& Bonache, 2016; Harzing, 2001), and such knowledge transfer is believed to be vital to subsidiary performance (Berry, 2015; Chang, Gong, \& Peng, 2012; Kawai \& Chung, 2019). Prior studies on the impact of expatriation on subsidiary performance have shown mixed results, using indicators such as expatriate number/ratio or the nationality of a subsidiary's general manager (Colakoglu \& Caligiuri, 2008; Fang, Jiang, Makino, \& Beamish, 2010; Gaur, Delios, \& Singh, 2007). Other studies have further developed this line of inquiry by considering whether specific expatriate characteristics, including skill and motivation, influence an expatriates' knowledge transfer to a subsidiary, and subsequently, subsidiary performance (Chang et al., 2012; Wang, Tong, Chen, \& Kim, 2009). While these quantitative analyses can show whether the number or certain characteristics of expatriates are associated with subsidiary performance, little attention has been paid to how they transfer knowledge, and why they are (not) effective in the process. In particular, we have a limited understanding of how foreign expatriates build social relationship with local employees, engage in interactions with them, and overcome cultural and language difference for successful knowledge transfer (Noorderhaven \& Harzing, 2009; Tsai \& Ghoshal, 1998).

Meanwhile, as global staffing practices are becoming more varied (Duvivier et al., 2019), inpatriation has received increasing attention in the IHRM literature as a complementary staffing practice to expatriation (Moeller \& Harvey, 2018). For example, Collings, McDonnell, Gunningle, and Lavelle (2010) report that $46 \%$ of their sample of 213 subsidiaries sent inpatriate staff to HQs. More recently, Harzing et al. (2016) show that expatriates and inpatriates are used to a similar extent: each subsidiary in their sample on average had 1.16 former inpatriates and 1.22 expatriates per 100 employees. There is also growing evidence that inpatriation is a useful means of disseminating and implementing HQ knowledge and shared corporate values throughout the MNC (Froese, Kim, \& Eng, 2016; Moeller \& Reiche, 2017; Sekiguchi, Takeuchi, Takeuchi, Nakamura, \& Ebisuya, 2019). The increasing use of inpatriation might reflect the changed purpose of global staffing from top-down information processing to continuous knowledge creation in MNCs (Nonaka, 1994).

While early studies focused on the motivation and significance of inpatriation (e.g., Harvey \& Buckley, 1997; Harvey, Speier, \& Novicevic, 1999), more recent studies have paid increasing attention to inpatriates' role as knowledge agents (e.g., Duvivier et al., 2019; Harzing et al., 2016; Reiche, 2006, 2011). Reiche's (2006, 2011) pioneering empirical studies in the context of German MNCs indicated that the primary objective of inpatriation is bilateral knowledge transfer. His exploratory findings pointed to the need to clarify the processes and determinants of knowledge diffusion between inpatriates and HQ staff through which inpatriates' knowledge agency is more likely to be effective. In addition, there is increasing evidence supporting inpatriates' role as effective knowledge agents. For instance, Harzing et al. (2016) integrate and extend existing insights by examining how the use of different assignment types (i.e., expatriation and inpatriation) affects $\mathrm{MNCs}^{\prime}$ knowledge transfer from and to $\mathrm{HQ}$, drawing on data from more than 800 subsidiaries of MNCs in 13 countries. An interesting finding of their study is that, compared to expatriates, the presence of former inpatriates appears to be more strongly related to knowledge transfer from and to HQ. Most recently, Duvivier et al. (2019) show how long-term and short-term expatriation and short-term inpatriation serve as complementary channels for transferring different types of knowledge over different time periods between HQ and foreign subsidiaries. In particular, their findings highlight that short-term inpatriation appears to be the most effective way of transferring different types of knowledge both during and after the assignment.

Although we know that inpatriates are effective in transferring knowledge in MNCs, we know little about how they do so and with what organizational outcomes. Without understanding the underlying mechanisms of inpatriates' knowledge transfer, we cannot explain why inpatriates appear to be more effective than expatriates in knowledge transfer from HQ to subsidiaries (Duvivier et al., 2019; Harzing et al., 2016). In addition, without knowing the performance-related outcomes of inpatriates' 
knowledge transfer, it is hard to evaluate the real value of inpatriation practices. MNC managers therefore lack research-based evidence of how inpatriates can be used in line with MNCs' strategic objectives. Thus, our study aims to gain an in-depth understanding of the processes and consequences of inpatriates' knowledge transfer over time, as most of the knowledge transfer from HQ to subsidiaries through inpatriation will occur after completion of the inpatriation assignment.

\section{Subsidiary Capability Building and Subsidiary Evolution}

To explore the performance-related outcomes of inpatriation, we draw on two important concepts from the global strategy literature: subsidiary capability building and subsidiary evolution. First, we define subsidiary capability building as developing a subsidiary's distinctive resources and unique skills through learning from other organizations and creating new business opportunities (Birkinshaw \& Hood, 1998; Luo, 2002). In the inpatriation context, the focus is on how subsidiaries build technical resources and skills through learning from HQ and create new business opportunities with local customers. Subsidiaries can benefit from HQ knowledge not only as a means to adopt and implement HQ values, policies and practices $(\mathrm{Mu}-$ dambi, 2002; Tran, Mahnke, \& Ambos, 2010), but also to serve as sources of competitive advantage for the wider MNC. Specifically, as discussed in the global R\&D literature, HQ knowledge is critical in the early stage of subsidiary growth. Subsidiaries utilize the knowledge created by $\mathrm{HQ}$ to develop their competences, and then combine HQ knowledge with external knowledge to innovate (Cantwell \& Mudambi, 2005; Kuemmerle, 1999). In this process, how subsidiaries build capabilities and expand their roles continues to be a key topic in the global strategy literature (e.g., Birkinshaw \& Hood, 1998; Strutzenberger \& Ambos, 2014). Because capabilities enhance firm performance (Teece, Pisano, \& Shuen, 1997), subsidiaries' capability building activities are essential for their survival and competitive advantage (Peng, 2003).

Second, subsidiary evolution is the result of an accumulation or depletion of capabilities over time (Birkinshaw \& Hood, 1998). A change in the composition of capabilities often leads to a concomitant change in the roles and responsibilities of a subsidiary within the MNC network, a process called subsidiary evolution. Global strategy scholars have categorized the different subsidiary roles and explained the evolutionary processes of these roles (Asakawa, 2001; Cantwell \& Mudambi, 2005; Nobel \& Birkinshaw, 1998). Examples include home-base exploiting/home-base augmenting units (Kuemmerle, 1999); competence-exploiting/competencecreating subsidiaries (Cantwell \& Mudambi, 2005); and starter/innovator/contributor (Asakawa, 2001). Although the determinants of subsidiary evolution have attracted significant research interest, the primary focus in these studies has been on macroeconomic and organizational factors, such as the local environment (location), subsidiary autonomy, and HQ mandates (Birkinshaw \& Hood, 1998; Cantwell \& Mudambi, 2005). In other words, how individuals act and interact to transfer or link knowledge in the process of subsidiary evolution has been largely ignored. Considering the importance of global staffing to MNCs' strategic objectives (Collings \& Isichei, 2017), studying the role of inpatriation in subsidiary capability building and subsidiary evolution is thus paramount. A better knowledge of the role of inpatriation in this process would provide a much-needed micro-foundational perspective to the question of how individuals' roles and actions facilitate knowledge transfer within MNC subsidiaries (Meyer, Li, \& Schotter, 2020).

\section{METHOD}

\section{Research Design}

To generate rich insights into the role of inpatriation in MNCs, we opted for a qualitative case study research strategy. The case study method was especially suitable given our aim to trace inpatriates' knowledge transfer activities over time, providing the opportunity to examine continuous processes in context and drawing on the significance of various interconnected constructs (Pettigrew, 1990). It also offers unique insights into how certain conditions change over time and towards a certain outcome (Soulsby \& Clark, 2011). A case study approach is therefore well suited for our research question, which is to explore whether and how inpatriates' knowledge transfer activities provide value to their subsidiary.

Our research context is Asian MNCs in the Asian region. While early empirical studies on inpatriation offered insights based on data from European and American MNCs (e.g., Cerdin \& Sharma, 2014; Harvey \& Miceli, 1999; Reiche, 2006, 2011), empirical efforts have recently expanded to Asia 
including Japan and Korea (Froese et al., 2016; Sarabi et al., 2017; Sekiguchi et al., 2019). Because of strong business growth and competitive pressures among global and local players in this region, there are increasing demands for MNCs to devise a more effective global staffing strategy to compete successfully in Asia (Budhwar \& Debrah, 2009; Varma \& Budhwar, 2013). This is especially the case for Japanese MNCs that have a long history and large numbers of foreign subsidiaries in Asia and have recently faced high competitive pressures. Since their early global expansion in 1960, the Asian region has been the major destination of Japanese MNCs. According to the Annual Report of Statistics on Japanese National Overseas (Ministry of Foreign Affairs, 2018), almost 70\% of all 75,531 Japanese MNCs' foreign subsidiaries are located in Asia. Although Japanese MNCs have enjoyed a dominant presence in many countries in Asia, this has been threatened especially by the emergence of MNCs from China, Korea, and Taiwan. Japanese MNCs therefore face urgent pressures to devise more effective global staffing strategies (Sekiguchi, Froese, \& Iguchi, 2016).

\section{Data Collection}

We followed recommendations by Yin (2003) and Miles, Huberman and Saldana (2014) for theoretical or purposeful sampling, thus focusing on a case's unique context with regard to inpatriation and subsidiary performance. To collect data that were as reliable as possible, we followed a three-phase process. In the first phase, we conducted 18 interviews to understand general inpatriation practices by Japanese MNCs and find a "revelatory" case (Yin, 2003). Based on a total of 47 Japanese MNCs that we investigated in previous research projects, ${ }^{1}$ we identified eight Japanese MNCs that use inpatriation as an established HRM practice and asked them for cooperation with our research. These eight MNCs did not differ from the other 39 MNCs in terms of size, industry (manufacturing), or age (64 years on average), thus they do not represent an atypical group. Seven of them agreed to join our study and provided access to their HR managers in the Japanese HQ and general managers in the overseas subsidiaries for our interviews. Between March 2013 and January 2016, we conducted 18 preliminary interviews in the seven Japanese HQs and their eleven subsidiaries (six in Korea and five in China) to understand how they operated and how they managed inpatriation. All seven MNCs operate in the manufacturing industry, and the eleven subsidiaries have product development and/ or manufacturing functions. In the Japanese HQs, we asked about the background, motivation, trends, and management of inpatriation in each $\mathrm{MNC}$ as detailed in Table $2 \mathrm{a}$ and requested access to those subsidiaries that exemplified best practices in managing inpatriation. Although these MNCs had subsidiaries in a wide range of countries, they all recommended us to visit their Korean and/or Chinese subsidiaries. Table 1 summarizes the inpatriation practices of the seven MNCs. From these preliminary interviews, we were able to observe that inpatriation was increasingly adopted by Japanese MNCs, showing a marked change from their conventional practice of heavy dependence on expatriates only in their global management (Kopp, 1994). As shown in Table 1, the subsidiaries mostly sent their engineers and technical staff to the Japanese HQ for a duration of 1-7 years to be trained on a specific product, project, or skill. The inpatriation of engineers and technical staff is due to Japanese MNCs' firm-specific advantages in product development, manufacturing operations and quality control, all of which entail highly tacit knowledge (Collinson \& Rugman, 2008) and require the movement of people to be transferred (Argote, 1999).

The preliminary interviews further revealed that both in the HQ and the subsidiaries directors and managers agreed that inpatriation is a highly effective approach to transfer knowledge from HQ to subsidiaries. However, how exactly inpatriates transfer knowledge and why they are especially effective remained unclear. Thus, after conducting interviews in the 11 subsidiaries, we selected two Korean subsidiaries (from MNC A-Co and B-Co, respectively) for an in-depth case study to understand the long-term process and consequences of inpatriates' knowledge transfer (Blazejewski, 2011). This was because subsidiaries of the other MNCs sent inpatriates on an irregular basis or had started the practice more recently (2008-2010), while A-Co's and B-Co's Korean subsidiaries had started inpatriation much earlier (around 2000), allowing us to draw on richer experience and data on the practice. In addition, the first author's ability to speak both languages (Japanese and Korean) fluently, and familiarity with both cultures provided a strong advantage for an in-depth investigation of these two subsidiaries. Hereafter, we call the two subsidiaries A-Sub and B-Sub.

In the second phase, we conducted 17 in-depth interviews with key informants in A-Sub and B-Sub 


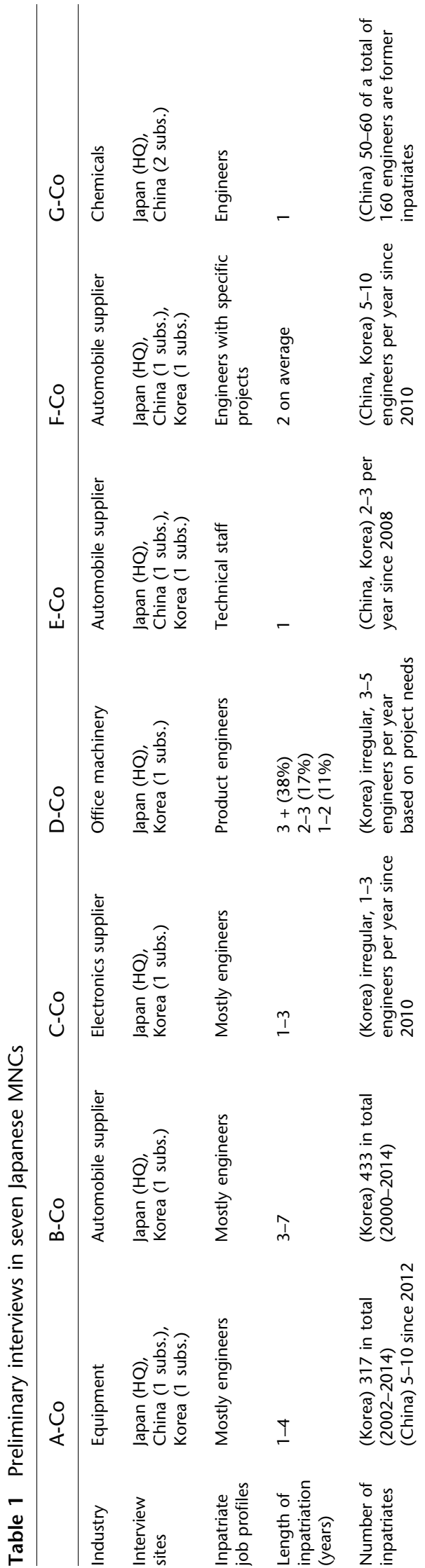

to address the main research question of our study, i.e., whether and how inpatriation contributes to subsidiary performance. In our research design, we faced the challenge of gathering data about both current and past practices of inpatriation and organizational change. Gathering data about past practices carries a risk of retrospective bias. However, Miller, Cardinal and Glick (1997) suggest that when conducted carefully, retrospective analyses of organizational phenomena are a valid and reliable means of gaining insights into organizational change. Further, organizational processes can be captured by what insiders say about their work experiences (Soulsby \& Clark, 2011). Consequently, we decided to adopt a retrospective data collection design, with concerted effort to prevent a potential retrospective bias by conducting interviews with a wide range of interviewees in various positions and triangulating our findings with time-stamped archival data. We drew on retrospective accounts of former inpatriates in a range of different positions and departments, as well as subsidiary managers to gain diverse perspectives into both subsidiaries' history, inpatriates' activities, and organizational changes/performance. Interviews were carried out in person in the meeting rooms of both subsidiaries in Korea between March 2015 and March 2018. The list of interviewees and the interview protocol are summarized in Table $2 b$.

Each interview lasted between 60 and $90 \mathrm{~min}$ and was recorded when permitted. Interviews were conducted in the native language of interviewees to build rapport and gather data that were as rich as possible (Welch \& Piekkari, 2006). In other words, all Korean inpatriates were interviewed in the Korean language while Japanese HQ staff and managers were interviewed in the Japanese language. The first author conducted all interviews. To avoid loss of data quality and richness, the first author performed the initial phase of coding in the interview language, and translated codes and selected quotes into English. Subsequently, the second and third author edited them to improve readability in English without losing their original meaning. The codes generated after the 6th interview in A-Sub and the 4th interview in B-Sub were minor variations of existing themes, which suggested to us that saturation had been reached (Mason, 2010).

In the third phase, we conducted five additional interviews in the HQs of both subsidiaries for triangulation, for a total of 40 interviews conducted. With these additional interviews we aimed 
Table 2 List of interviewees and interview protocol

\begin{tabular}{|c|c|c|c|c|}
\hline Org. & No. & Year of interview & Site & Participants \\
\hline \multicolumn{5}{|c|}{ (a) Phase 1 preliminary interviews in seven MNCs (2013-2016) } \\
\hline \multirow[t]{3}{*}{ A } & 1 & 2013 & Japan HQ & Managing Director, HR Manager \\
\hline & 2 & 2016 & China & General Manager, Factory Manager, Sales Manager, Engineering Director \\
\hline & 3 & 2013 & Korea & General Manager, HR Manager, Engineering Manager \\
\hline \multirow[t]{2}{*}{ B } & 4 & 2013 & Japan HQ & Administrative Manager, Factory Manager, HR Manager \\
\hline & 5 & 2015 & Korea & General Manager, Deputy General Manager, Engineering Manager \\
\hline \multirow[t]{2}{*}{$\mathrm{C}$} & 6 & 2014 & Japan HQ & HR Manager, HR Assistant Manager, Factory Director, Senior Advisor \\
\hline & 7 & 2015 & Korea & General Manager \\
\hline \multirow[t]{2}{*}{ D } & 8 & 2015 & Japan HQ & Managing Director \\
\hline & 9 & 2015 & Korea & General Manager, Engineering Manager, Factory Director, HR Manager \\
\hline \multirow[t]{3}{*}{$\mathrm{E}$} & 10 & 2013 & Japan HQ & Senior Managing Director, HR Manager, HR Director, Factory Manager \\
\hline & 11 & 2016 & China & General Manager, Engineering Manager, HR Manager \\
\hline & 12 & 2013 & Korea & General Manager, Engineering Manager \\
\hline \multirow[t]{3}{*}{$\mathrm{F}$} & 13 & 2014 & Japan HQ & Managing Director, HR Manager \\
\hline & 14 & 2015 & China & General Manager, Factory Manager \\
\hline & 15 & 2015 & Korea & General Manager \\
\hline \multirow[t]{3}{*}{ G } & 16 & 2014 & Japan & HR Manager \\
\hline & 17 & 2015 & China & General Manager, Deputy General Manager \\
\hline & 18 & 2016 & China & General Manager \\
\hline
\end{tabular}

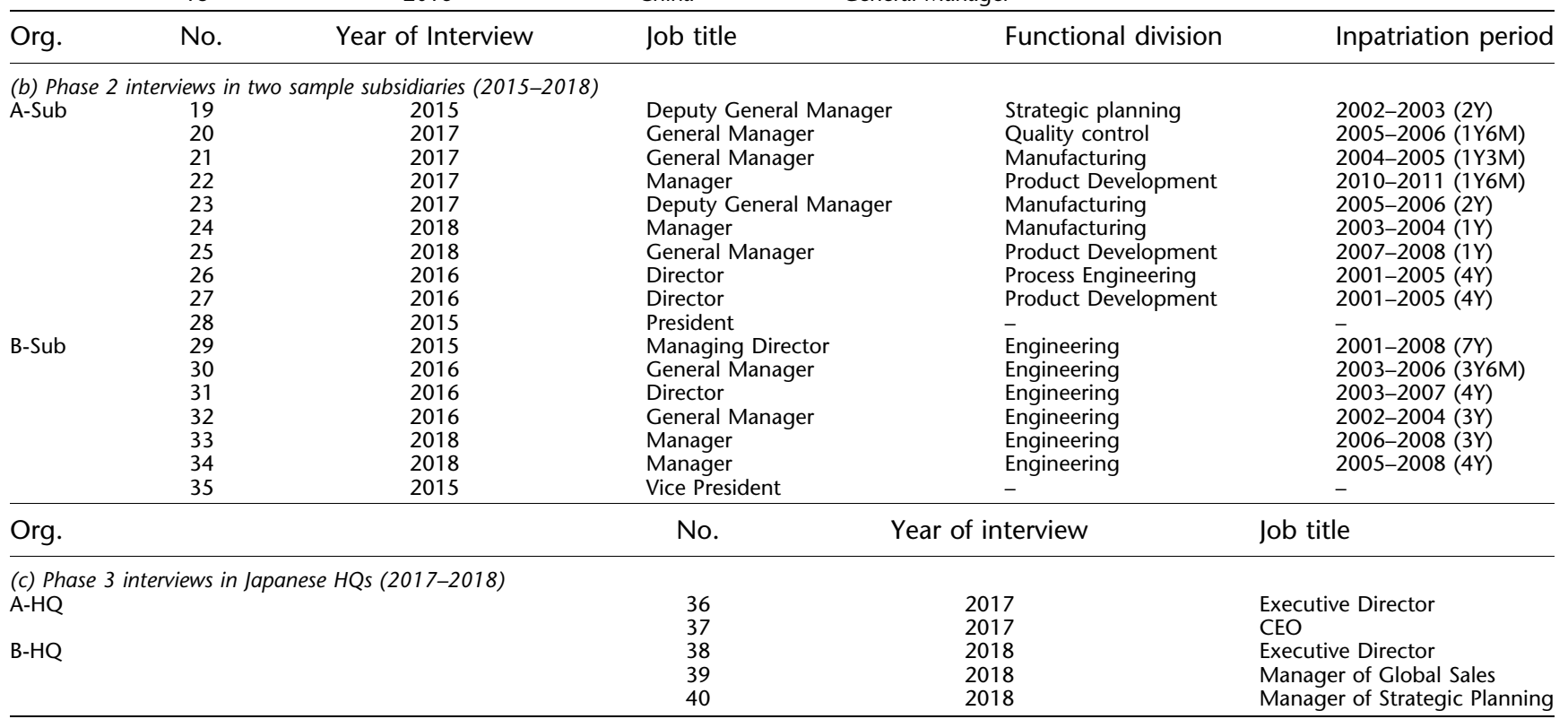

Extract of interview protocol for managers at $H Q$

(1) What is the background and motivation of inpatriation practices in your company?

(2) How many inpatriates, and from which countries, work in $\mathrm{HQ}$, and what kind of tasks do they have?

(3) How does the role of inpatriates differ from expatriates or other forms of international assignees?

(4) Have you noticed any changes in the HQ organization since inpatriation has started?

(5) Please provide a few examples for how inpatriates have proved especially effective or helpful.

Extract of interview protocol for managers at subsidiaries

(1) What is the background and motivation of inpatriation practices in your company?

(2) How do you select inpatriates and what do you expect them to do upon repatriation?

(3) To what extent do Japanese expatriates and former inpatriates take different roles in your operations?

(4) How would you evaluate the performance of former inpatriates (compared with other managers) and why?

(5) What challenges do you face in managing inpatriation?

Extract of interview protocol for former inpatriates at A-Sub and B-Sub

(1) What is your educational and career background and experience, and the motivation/ purpose/duration of the inpatriation?

(2) What is your experience as an inpatriate in Japan: your work details, relationship with colleagues and life more broadly. What was most challenging, and what was most beneficial to you?

(3) What have you learned and achieved while working in Japan? How did you make use of the learning after returning to your original unit?

(4) What was your role after coming back go your original unit? How did your tasks and responsibilities differ before and after inpatriation?

(5) How do you evaluate your overall experience as an inpatriate and why? How can the inpatriation practice be improved?

Extract of interview protocol for directors and managers at $A-H Q$ and $B-H Q$

(1) What is your career background and your involvement with overseas subsidiaries including A-Sub and B-Sub during your work experiences.

(2) How does the HQ support subsidiaries' growth and the knowledge transfer between HQ and subsidiaries?

(3) How do you perceive the roles of A-Sub and B-Sub in your global network and how do you evaluate their performance?

(4) To what extent do you think the inpatriation practice contributed to A-Sub's and B-Sub's growth? Why?

(5) What changes do you foresee for your global HRM policies in the future? 
to cross-check the earlier interview data, especially regarding subsidiary capabilities, performance, and roles as evaluated by the HQ as detailed in Table 2c. These interviews were conducted in both A-Sub's and B-Sub's Japanese HQs (hereafter called A-HQ and B-HQ), with two board members in A-HQ and one board member and two managers of the global sales and strategy departments in B-HQ in 2017 and 2018, respectively. In sum, our three-phased interview approach provided rich data to understand inpatriates' activities and the histories of the two case subsidiaries, with our interviews in the second and third phase serving as the focus of our subsequent data analysis. The interview data were used to capture how inpatriates transfer knowledge from HQ to subsidiaries.

In addition to the interview data, we used secondary data with the following purpose. First, the two subsidiaries' internal documents regarding their HRM policies (selection criteria of inpatriates, inhouse training, number of inpatriates sent annually, etc.) served to understand the purpose and trends of inpatriation. Second, to understand the subsidiaries' business activities and performance, 2000-2018 data from company websites, press releases, annual reports, industry magazines and Facebook were collected. These data provided ample evidence of the subsidiaries' successful performance, such as regular new product launches, financial performance, awards, and industry ranking. Third, we were provided with internal documents that showed a chronological change of the manufacturing-related quality index such as annual sales, defect rate, and average manufacturing lead time, which were used to triangulate our interviewees' accounts about improved operational capability. Taken together, we used these three types of time-stamped archival data to examine the background, inpatriation policies and trends, and the performance of A-Sub and B-Sub.

\section{Data Analysis}

As we tried to make sense of the stream of data, focusing on the process of 'how inpatriates function and how and why this changed over time', we structured our data along two phases: during and after inpatriation. Process research attempts to provide explanations in terms of the sequence of events leading to an outcome (e.g., do A and then B to get C) (Langley, 1999, p. 692). We thus organized our data to illuminate 'who did what' (inpatriates' activities at HQ), 'what happened' (inpatriates' activities after returning to their original subsidiary), and 'with what outcome' (subsidiary performance). Langley (1999) labeled this as a 'temporal bracketing strategy' to suggest that the decomposition of data into successive adjacent periods would enable the explicit examination of how actions in one period led to changes in the context that will affect actions in subsequent periods.

Taking an in vivo (Andersen \& Kragh, 2011) or abductive (Piekkari \& Welch, 2017) approach, we iterated among the data, emergent theory, and literature to derive a logical explanation of the emergent relationships among the constructs. Using the qualitative data analysis software NVivo 12 , our detailed process of data analysis started by using an 'open coding' technique to group the data under key concepts and labels (Glaser \& Strauss, 1967). All first-order codes were in vivo codes (i.e., verbatim terms used by the respondents, Strauss \& Corbin, 1998). For instance, one code was "Learn about new projects/product knowledge" (i.e., the participants used these exact words), which was then coded as any product-related information ("I learned about new product knowledge"), or information that we interpreted as related (e.g., "Getting a better understanding of detailed design and processes was the primary purpose"). In the next step, such first-order codes were merged into second-order themes, many of which were inspired by theoretical concepts reflected in the data. For example, the statement "because they have both language proficiency and experiences, they learn much faster" generated the first-order code "Enhanced learning/understanding capability" and was then grouped into the second-order code "Subsidiary absorptive capacity". These second-order themes were finally aggregated into three higherorder themes: short-term functions of inpatriation, long-term functions of inpatriation, and consequences of inpatriates' knowledge transfer. Throughout the process, codes were refined through constant iterations between theory and data, in which fresh conceptual understandings were gained. The coding schemes and sample quotations are presented in tables in the following section.

\section{FINDINGS}

In this section, we present our research findings. We start by introducing the background and trends of the inpatriation practices in the two case study subsidiaries, focusing on four common features. Subsequently, we explain how short-term functions 
of inpatriation developed into long-term functions, which eventually contributed to subsidiary capability building and subsidiary evolution.

\section{Subsidiary Background and Inpatriation Trends}

Although A-Sub and B-Sub belong to different industries (semiconductor/electronic equipment and automobile parts, respectively) and have no business relations, they share four commonalities in terms of their inpatriation practices. First, when the two subsidiaries were established, they both had market-seeking responsibilities (Birkinshaw, Hood, \& Young, 2005). A-Sub was established in 1995 as a sales unit without a manufacturing function or facility at all, while B-Sub was established in 1998 as a liaison office to seek a market opportunity in Korea. This can be inferred from the following quote from a manager of B-Sub:

\begin{abstract}
I joined B-Sub in 1999, the year of establishment. The office was in the center of Seoul, and there were 30 empty desks when I went there. One president, one secretary and me, that was all. Then, we started to recruit engineers to fill the empty desks. [...] Around 2000, B-Sub's existing business with Japanese automobile makers did not have much room for further expansion, and Korean automobile makers were growing fast in the global market. So, our initial mission was to search for a business opportunity with Korean automobile makers such as C-Auto and D-Auto. (\#29)
\end{abstract}

Second, both subsidiaries strategically started inpatriation from the very early stages of their establishment, sending a number of engineers to the Japanese HQ in a successive manner, and on a longer-term basis than the other subsidiaries. That is, the average length of inpatriation in these two subsidiaries was about 3 years, compared to 1-2 years in the case of the other subsidiaries in Table 1. In A-Sub, 317 employees experienced an inpatriation assignment of between 1 and 4 years of duration in the period between 2002 and 2014. Similarly, B-Sub sent 433 employees in total to the Japanese HQ for 3-7 years in the period between 2000 and 2014. Explaining this extraordinarily high number of inpatriates, A-Sub's and B-Sub's managers described their early days at the two subsidiaries as follows:

\footnotetext{
In those days, we employed many, and sent many [to the Japanese $\mathrm{HQ}$ ]. Learning from Japan was the primary purpose of it, as we had nothing, and were really desperate to learn from their [HQ] experience and technology. (\#19)

At the beginning, there were few things to do here [in B-Sub]. We had just started, so no experience, thus no task given. Until we took off with our work with customers in Korea in 2005-2006, doing OJT [on the job training] in Japan was very normal. (\#29)
}

Third, as Figure 1a and b clearly show, very similar patterns of change in inpatriate numbers could be observed in both subsidiaries. There was a phase of increased inpatriation for 5-6 years and a phase of decreasing numbers for 3-4 years, followed by a stable phase. This suggests there were changes in both organizations in terms of the necessity of inpatriation.

Fourth and finally, at the time of our interviews at A-HQ and B-HQ in 2017 and 2018, both A-Sub and B-Sub were highly evaluated by their respective HQ managers in terms of their fast sales growth supported by strong manufacturing and R\&D capability. Having started as a sales unit, A-Sub extended its capabilities into manufacturing and product development. Similarly, B-Sub initially was a liaison office, but developed into an $R \& D$ unit with the highest R\&D capabilities among B-Co's overseas subsidiaries. These four commonalities of A-Sub and B-Sub suggest that their strategic practice of inpatriation contributed to the subsidiaries' capability building, a process which we will elaborate on in the following sections.

\section{Short-Term Functions of Inpatriation: Acquiring Individual-Level Knowledge}

The first theme that arose from our data analysis related to what we have coded as the short-term functions of inpatriation. This involved the different categories of knowledge which our informants individually acquired when working as inpatriates at the HQ. As individuals are the principal knowledge repositories and prime movers of knowledge flows within organizations (Foss \& Pedersen, 2019), individuals' knowledge acquisition is a critical starting point. Their individual knowledge acquisition consisted of three categories: task knowledge, language/cultural knowledge, and relational knowledge. Our coding schemes and empirical evidence are summarized in Table 3.

First, acquiring task-related knowledge was the primary and explicit purpose of inpatriation. Thus, in most cases, inpatriates were sent to HQ with specific missions, including acquiring knowledge about new products/technologies, and developing skills in specific functions (e.g., product development projects, sales engineering, quality control). However, this knowledge acquisition is very different from a short-term inhouse training course. Korean inpatriates in our sample joined project teams in Japan and worked for 1-7 years in the same way as HQ staff, learning the relevant tasks by 
(a) Number of inpatriates and performance in A-Sub

The number of inpatriates and annual sales (A-Sub)

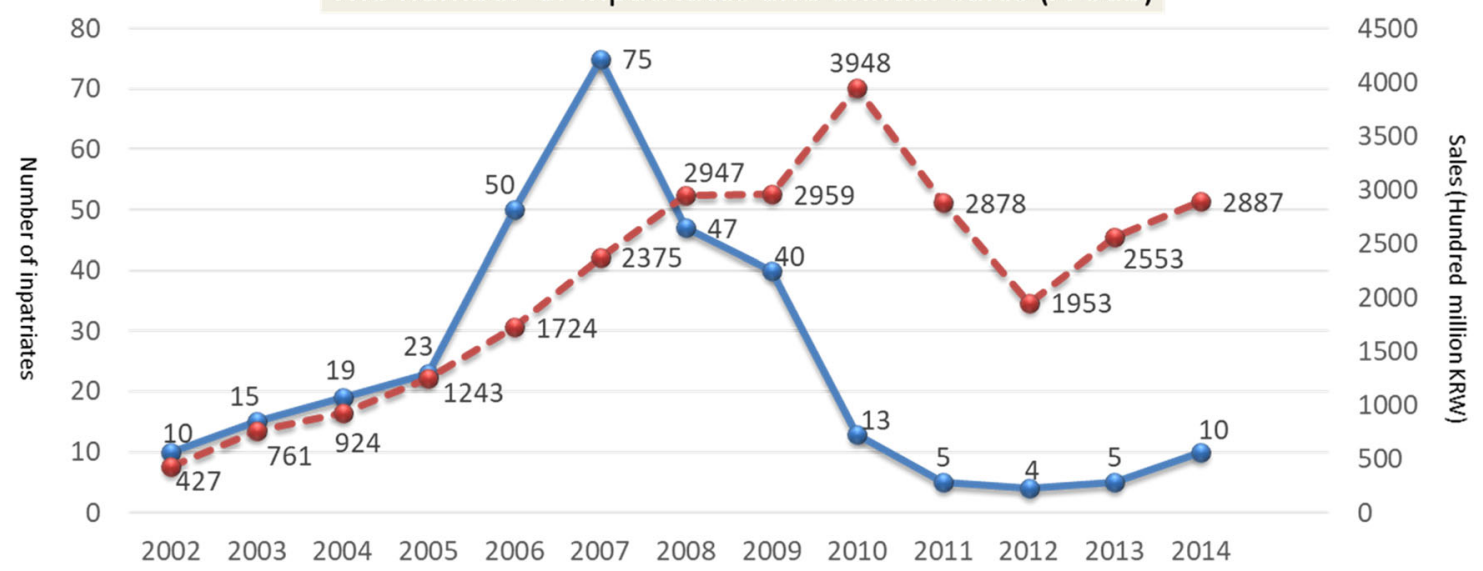

-No. of inpatriates - Sales (Hundred million KRW)

\section{Defect rate}

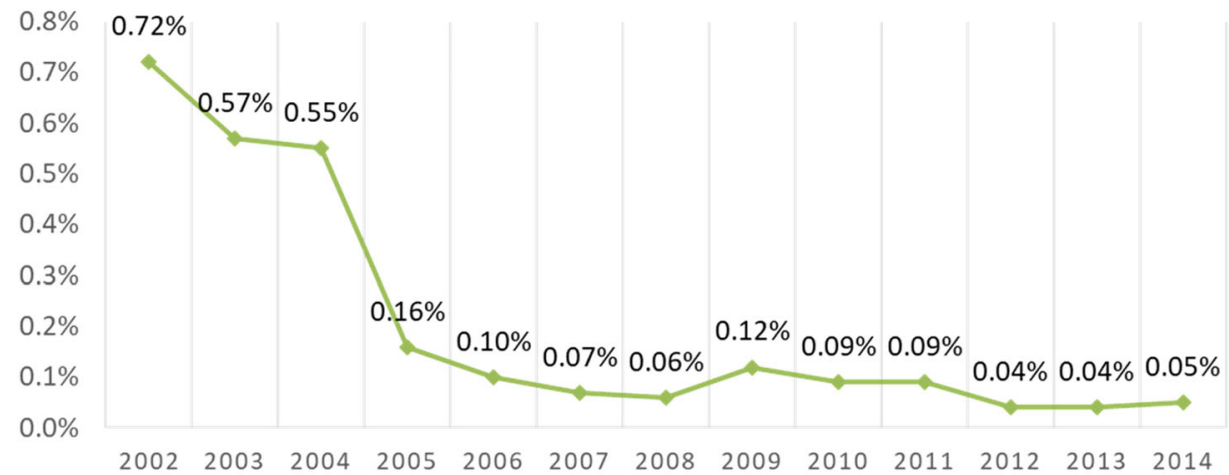

(b) Number of inpatriates and performance in B-Sub

The number of inpatriates and annual sales (B-Sub)

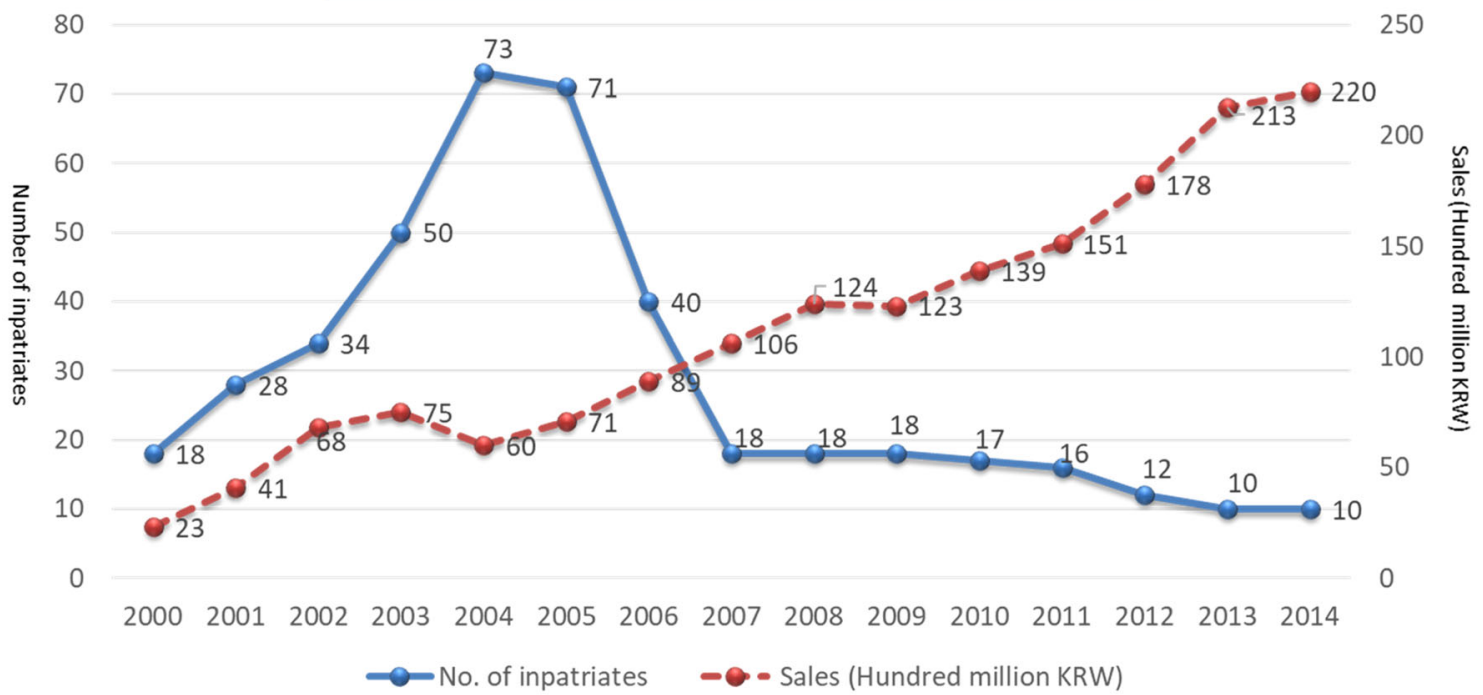


$\triangle$ Figure 1 a Number of inpatriates and performance in A-Sub. Note: The number of inpatriates in 2014 was temporarily increased at HQ's request for a specific project and then declined to 3-5 people annually. The plunge in annual sales in 2011 and 2012 was caused by an industrial recession and has recovered since. $\mathbf{b}$ Number of inpatriates and performance in B-Sub. Source: Internal documents provided by A-Sub and B-Sub.

doing in the process. In particular, many former inpatriates pointed out that working at the HQ enabled them to understand the underlying rationale of specific tasks and procedures through action and practice. The following quote exemplified this:

\begin{abstract}
Written processes are just minimum necessary conditions, but to finish a product [development] there are lots of invisible paths and hidden meanings [underlying rationales]. I got to grasp the 'sense' [while working in the HQ]. (\#30)
\end{abstract}

It is also noteworthy that inpatriates acquired proficiency in the parent company's national language and deepened their knowledge of the national/corporate culture. Many informants mentioned language and cultural knowledge in the same vein, suggesting that there are synergies in the concurrent learning of both. The acquisition of language/cultural knowledge provides a basis for making technical and cultural sense of the communication among participants. In addition, it lays an important foundation for inpatriates to transfer knowledge effectively, because without the ability to bridge cultural differences, the meaning of the intended knowledge can be misinterpreted (Liu \& Meyer, 2020). One B-Sub manager described his learning about language and corporate culture as follows:

\begin{abstract}
Working in the Japanese language was the most challenging thing at the beginning. I recorded all the meetings that I attended, listened to them after work, and when I ran into words that I didn't know I looked them up in a dictionary. A feeling of urgency drove me to work hard on it, and I think I made fast progress. [...] I got to know the total system of the company. How it works, why it works in that way. How to make a decision in Japan [B-HQ] was totally different from the way in Korea [B-Sub]. They [staff at the HQ] have lots of discussions all the time, and those discussions contain lots of important information, however only the conclusion is shared with subsidiaries. (\#34)
\end{abstract}

Inpatriates also built relationships with HQ colleagues through frequent interactions and acquired relational knowledge as a result, which is defined as knowledge of "who knows how to do what" (Duvivier et al., 2019; Lundvall \& Johnson, 1994). In our data, former inpatriates largely reported two types of relational knowledge: who does what (individual roles) and who knows what (experience and knowhow that individuals possess). Through close in-company interactions, they learned who takes what kind of roles in the process of task completion and decision-making and who has specific expertise about tasks, products, customers, or technology, as shown in the following quote:

If I pick up the most important thing I have learned in Japan, that is 'how to get approval for your proposal'. Who is in which department/team, who knows what, and who can decide what? Without knowing this, however brilliant your proposal is, it will never get approved. (\#29)

Of course, the acquisition of task knowledge, language/cultural knowledge and relational knowledge is a mutually reinforcing process. For example, inpatriates were able to build relationships at the HQ and acquire relational knowledge, because they were embedded in the organization as long-term inpatriates, not as short-term visitors during a business trip or a training, and thus had daily formal and informal interactions with HQ staff. Their language/cultural knowledge improved in the process of acquiring task and relational knowledge, thereby further accelerating the other two functions. But how did inpatriates convert this individually acquired knowledge into organizational-level knowledge after they returned to their original unit? We will elaborate on this next.

\section{Long-Term Functions of Inpatriation: Converting Individual to Organizational Knowledge}

Knowledge transfer is not automatic, but depends on specific catalysts (Szulanski, 1996). Thus, simply transferring inpatriates from $\mathrm{HQ}$ back to their original subsidiaries is unlikely to lead to knowledge transfer. In this section, we focus on how inpatriates diffuse their individually acquired knowledge into their original subsidiary to transfer and create knowledge in the specific subsidiary context. We identified two long-term functions of inpatriation: building subsidiary absorptive capacity and maintaining access to information. Our coding schemes and empirical evidence are summarized in Table 4.

First, former inpatriates disseminated what they learned at the HQ to the other subsidiary employees, thereby helping to enhance absorptive capacity of the entire subsidiary organization. Absorptive 
Table 3 Short-term functions of inpatriation: coding scheme and empirical evidence

\begin{tabular}{ll}
$\begin{array}{l}\text { Second-order } \\
\text { themes }\end{array}$ & First-order codes \\
\hline Task knowledge & $\begin{array}{l}\text { Learn about new projects/ } \\
\text { product knowledge }\end{array}$
\end{tabular}

Sample quotations

Learn underlying rationale of tasks and procedures

Language/cultural knowledge product knowledge

Gaining a better understanding of detailed design and processes was the primary purpose. Before I went to the Japanese HQ, I knew, let's say, how some basic product models are roughly designed, but not very much in detail. So, we needed to ask the HQ whenever our customers had some troubles that we cannot handle. We wanted to work more independently. (\#25) B-Sub sent me to the B-HQ just 6 months after I joined the company. In Japan, I worked 3 and half years developing CVT (Continuously Variable Transmission). Working everyday as a member of the human network in the HQ, I got to know how the product development process actually works. (\#30)

I've learned a lot about a very detailed product development process. Which step is more important [than others], and why it is more important, those are not written anywhere. But it matters a lot, actually. (\#22)

The way of working is quite different between Korea and Japan in general. Even though B-Sub is a subsidiary of a Japanese company, I got to know the difference after I went to work in Japan. For example, in Japan, they have very frequent checks to confirm whether everything is going as planned. However, in B-Sub, speed is more required. (\#34)

Language was a critical bottleneck at the beginning. It was impossible to learn from Japan because most of us did not understand their language, and few staff at the HQ speak English. Inpatriation was killing two birds with one stone, language and technical know-how. (\#19)

When I was first employed in 2005, I did not know the Japanese language at all. I had a high score in English instead. However, surprisingly, all PCs at B-Sub were set in Japanese language. I could not believe it but couldn't help learning it to survive. The speed of work was very slow, which was really frustrating. Now, after working in Japan for 3 years, I can even be a Japanese language teacher. (\#33)

Cultural understanding

I had read some books and already knew that Japanese people prefer to communicate in an indirect manner. However, I only understood the real meaning of it after I had the experience of working in the HQ. For example, 'yes' does not mean 'approval' or 'agreement' but means 'let's start to think or talk about it.'. (\#27)

Coordinating among the two groups [B-HQ and B-Sub] was difficult without sharing values and sentiments. For example, you know, the uneven balance of power between a supplier and a client is much bigger in Korea than in Japan. Thus, staff in Japan could not understand why something very unfair happened all the time with clients in Korea. Although these things are not as visible as a transmission product or technology, they are fundamental, critical. I learned them working at the HQ. (\#32)

Although I had worked with my Japanese boss in A-Sub before [going to Japan as an inpatriate], I could actually get to know how the relationship works in Japan, and the fact that it is everything. For example, before the inpatriation, I have complained a lot about very late responses or no responses from the HQ about our inquiries or suggestions. The problem was, we [A-Sub staff] did not know the right person to ask. (\#23)

The basic frame of the product development process is the same [in the HQ and the B-Sub]. However, I think the most fruitful thing during my inpatriation was learning who takes care of which processes and makes which outputs. There are 'gates' in each development processes and essential requisites should be cleared to pass the gates. I got to know how to get these essential requisites, to which degree it should be completed, and most importantly, who needs to do that. (\#32)

I have worked in an engineering team [of the HQ] for 4 years and could meet legendary senior engineers who have developed the very product we [A-Sub] 
Table 3 (Continued)

Second-order First-order codes

themes
Sample quotations

mainly manufacture or a recent new model we started to manufacture. They told me a lot about what kind of troubles they had experienced in the process of product development and mass production. There is a vast amount of experience and databases in $\mathrm{HQ}$, but we had no idea, thus we had suffered from similar troubles before. There would have been no way to know this if I had not worked in the HQ. (\#26)

One of the major projects of our team [in the HQ] was developing an application model for Renault's new vehicle. It was a challenge for me because I had almost no idea about European customers. One day, the chief of my team introduced me to Mr. T of another team who has worked in our French subsidiary about 5 years. He became my teacher, he knows everything how to work with the Renault team. That's how I can lead the Renault project in B-Sub now. (\#33) capacity is defined as the ability of a firm to recognize the value of new, external information, assimilate it, and apply it to commercial ends (Cohen \& Levinthal, 1990). In our context, it refers to subsidiary members' ability to access and acquire technical knowledge from the HQ and apply it to the business with local customers. As the number of former inpatriates increased in the subsidiaries, a cycle of inhouse knowledge transfer was established, whereby former inpatriates acted as teachers or trainers. In many cases, they led a project team with junior colleagues, diffused the knowledge they had acquired at the HQ to others, and interpreted the HQ's technical knowledge in the local market context. In this process, former inpatriates externalized their acquired knowledge and passed it on to their junior colleagues who internalized it to some degree. This laid the foundation for building absorptive capacity of subsidiaries, enhancing junior colleagues' abilities and motivations (Minbaeva, Petersen, Björkman, Fey, \& Park, 2003). According to Nonaka's (1994) organizational knowledge creation theory, "the field" or "selforganizing team" is critical for creating organizational knowledge, because "communities of interaction" contribute to the development of new knowledge by amplifying and expanding individual knowledge. In the team process, focused training with instructors and colleagues consists of repetitive exercises that stress patterns of behavior and the establishing of such patterns (Nonaka, von Krogh, \& Voelpel, 2006). In our study, team activities led by former inpatriates in the process of a specific project stimulated knowledge conversion from the individual to the group level, thereby enhancing subsidiary absorptive capacity.

This cycle of inhouse knowledge diffusion, and the resulting increase in absorptive capacity, help explain the changing pattern of inpatriation in Figure 1, where the number of inpatriates showed a sharp increase before decreasing again, followed by a stable phase maintaining a small number of inpatriates thereafter. In other words, the necessity of a continuously large number of inpatriates decreased to the extent that former inpatriates could teach their junior colleagues. Only when there was the need for further knowledge acquisition about a new technology or product, additional inpatriation occurred, but on a much smaller scale. In these cases, inpatriates were much better prepared in terms of technical knowledge, work experience and language before even relocating to HQ, making their knowledge acquisition at the HQ far more effective compared to the early days of inpatriation. One director of A-Sub explained his experiences as follows:

I worked in the HQ for 4 years and had countless customer meetings and learned a lot about technical sales and engineering. Since I came back [to A-Sub] in 2005, I became a team leader of manufacturing semiconductor equipment, mostly business with C-Elec. There were four junior engineers in our team, and I taught them. Not only about technological things, but also about how to work with HQ staff. (\#26)

At the same time, former inpatriates ensured a continued flow of information between the HQ and the subsidiaries, by nurturing the social capital i.e., the structure and content of individuals' 
Table 4 Long-term functions of inpatriation: coding scheme and empirical evidence

\begin{tabular}{ll}
\hline Second-order themes & First-order codes \\
\hline $\begin{array}{l}\text { Building subsidiary } \\
\text { absorptive capacity }\end{array}$ & $\begin{array}{l}\text { Accumulation of former } \\
\text { inpatriates }\end{array}$ \\
& \\
& $\begin{array}{l}\text { In-house cycles of teaching } \\
\text { and learning }\end{array}$
\end{tabular}

Sample quotations

Everyone in top management now is a former inpatriate. They decided to continue this practice because they experienced it, and they best know how effective it works for themselves, and for our organization. (\#20)

Although some former inpatriates were headhunted by other companies, most of them stayed and were promoted to management level. (\#29) and learning

Naturally, not all of them, but most former inpatriates became team leaders or managers, and newly employed staff were taught and supervised by them. (\# 19)

After coming back to B-Sub, we started to deal with projects with customers in the Korean market by ourselves. From around 2004, our business with C-Auto and D-Auto has increased. At that time, former inpatriates and newly employed engineers made a good team to develop our own projects with those customers. (\#32)

Enhanced learning/ understanding capability

Maintaining access to information
Continued social capital at HQ

Feeling part of a team with HQ staff

Improved speed and quality of communication
Since around 2007, the evaluation criteria for inpatriates got clearer and stricter. Only engineers of certain level of Japanese language proficiency and three to 5 years of working experience can go to Japan. It's more competitive than before. However, as there are many former inpatriates in A-Sub, junior staff learn from them easily. And, if really necessary, then they go to Japan. Because they have both the language proficiency and the experience, they learn much faster. (\# 25)

I remember it was about 2005 or 2006 when we felt that we can start our own project with support from the Japanese $\mathrm{HQ}$. That means we became confident that we could not only understand the HQ's knowledge but also utilize it in the Korean market. (\#31)

When I need some information from $\mathrm{HQ}$, I hesitated before, and sometimes just decided not to ask. It takes more nerve to ask someone you have never met, you know. It's much more comfortable now that I have some colleagues at the HQ. Through them, I can make quicker and easier access to anyone. (\#23)

About 10 years ago, when I was at the $\mathrm{HQ}$, I was in a project team with about ten members, for 3 years. Now my former colleagues work in various different departments. When I go to HQ for a business trip, my former colleagues introduce me to their present team members. Thus, I feel I have a much wider network at the HQ than before. (\#33)

Experiencing face-to-face communication changed things a lot. Before, they [staff in Japan] seldom replied to my questions, but of course I only knew their name, not their face. Now, we know each other, and have a feeling of being colleagues, being a team. (\#25)

When I worked at the HQ, I was an assistant manager and my boss was the general manager. I'm now deputy general manager of A-Sub, and the ex-boss is a board member at the HQ. Ten years have passed since we worked together at the HQ and our trust has strengthened, I feel. Whenever we meet, the ex-boss proudly says 'Oh, you've grown up'. (\#19)

Working 1-2 years in Japan and coming back to Korea makes communication very smooth and fast. We can get a response much quicker because now we ask someone at the $\mathrm{HQ}$ we already know. Also, knowing to ask 'what' to 'whom' significantly enhances the speed and effectiveness of work. (\#27) I got the feeling - well, confidence - that 'it's time to return inpatriate engineers to B-Sub and do our own projects.' I led the C-Auto project in 2008, and I felt about $80-90 \%$ of the tasks we could deal with our customer independently. When I needed something, to ask or request from staff at the $\mathrm{HQ}$, they quickly tossed back what we wanted, and it was very pleasant, smooth. (\#29) 
networks (Adler \& Kwon, 2002) - that they had developed while working at the HQ. Because information serves as a critical resource that is embedded in a person's network, inpatriates' continued social capital at HQ is a necessary condition for enabling the ongoing conversion of individual to organizational knowledge. Most of our informants reported that they kept in touch with their former colleagues at the HQ formally (e.g., through business calls, e-mail, video conference, meetings) and informally (e.g., through private calls/meetings, social network service contacts). Due to these continuous interactions even after return to their original units, these former inpatriates could further strengthen the feeling of 'being part of one team' with their HQ colleagues. Former inpatriates seemed to have a strong motivation to maintain their networks, as stated by a director of B-Sub:

Knowing from whom I can get help is big. Through lots of face-to-face talks and meetings, we could build a team spirit. I think this is the biggest [advantage of inpatriates]. A technology gets old as a new technology rises; I need to stay updated. Usually, the HQ has state-of-the-art information, so building a network, keeping the relationship with staff at the HQ is more important than learning a specific technology. (\#31)

This continued access to information by former inpatriates made communication between the HQ and the subsidiaries smooth and speedy. One manager of B-Sub expressed his confidence in being able to use technical knowledge and know-how that the HQ accumulated with the following metaphor:

\begin{abstract}
Keeping the linkage with the HQ is still very critical because the HQ has rich storage of technology and experiences. Now, we know what is in which drawer, and how to pull it out. (\#34)
\end{abstract}

By maintaining access to information, former inpatriates experienced a transition from being a temporary associate at the $\mathrm{HQ}$ to becoming a permanent foreign associate after they returned to their original units. In sum, we observed that these two long-term functions of inpatriation interact and reinforce each other. The more team projects were launched in subsidiaries, the more frequent communication with HQ would be necessary in order to source information. Moreover, the smoother and speedier the access to HQ information is, the more opportunities subsidiaries have to explore the adaptation of HQ knowledge to the local market and customers. The virtuous cycle of these two functions further stimulates former inpatriates' knowledge conversion, resulting in enhanced subsidiary absorptive capacity.

\section{Consequences of Inpatriates' Knowledge Transfer: Subsidiary Capability Building and Subsidiary Evolution}

The aforementioned short-term and long-term functions of inpatriation resulted in subsidiary capability building and subsidiary evolution. In our research context, subsidiary capability building refers to the expansion of functions, products and customers by developing technical resources and skills in the subsidiaries. Meanwhile, subsidiary evolution is the result of an accumulation of capabilities over time, which leads to a change in the roles and responsibilities of a subsidiary. For instance, subsidiary evolution occurs when a home-base exploiting unit changes its role to a home-base augmenting unit (Kuemmerle, 1999). Our coding schemes and empirical evidence are summarized in Table 5.

First, the short-term and long-term functions of inpatriation facilitated capability building in A-Sub and B-Sub through the development of resources and skills in terms of function, product and markets. A-Sub, which was initially a sales office, built the technological resources and skills to become a subsidiary with high-end product manufacturing capability and, more recently, even an R\&D function. Not only did the subsidiary successfully expand its functions, but it also increased the quality of each function. For example, secondary manufacturing quality data that we were able to access suggested that the defect rate of final products continuously improved over time and was at its lowest level in A-Co's overseas subsidiaries at the time of the interviews as shown in Figure 1a. Similarly, B-Sub was a liaison office seeking market opportunities at the beginning, but later acquired the capabilities to grow into a self-sufficient subsidiary that could manage a whole product development process, the only case among B-Co's overseas subsidiaries. A director of A-Sub described their past growth and continuing challenges as follows:

We were a mere sales office around 2000, but now we manufacture various equipment for domestic and neighboring markets, with the lowest defect rate among our global group companies. An R\&D unit was established a few years ago, and it's small, only eleven engineers now. But we are sure that we have enough technological resources and experiences to further develop the R\&D function. We want to do something that the HQ cannot do. (\#27) 
Table 5 Consequences of knowledge transfer through inpatriation: Coding scheme and empirical evidence

Second-order First-order codes $\quad$ Sample quotations
themes

themes

Subsidiary

capability

building
Functional extension

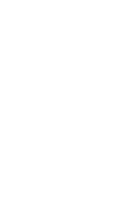

extension

Customer extension

Evolution of subsidiary role
Increased collaboration with $\mathrm{HQ}$ staff

Support sister subsidiaries

Improved status/importance in the company network
At the beginning, when A-Sub started to manufacture equipment, people in the Japanese headquarters opposed the idea because they thought it's far beyond A-Sub's ability. They said 'No, don't do that.' However, as the number of inpatriates to Japan increased and they brought back what they learned in Japan to A-Sub, we have made dramatic progress. The first and second equipment which was manufactured in A-Sub used 100\% Japan-imported parts. Then, we tried to localize parts from the third equipment. Now, we source $95 \%$ of parts in Korea to manufacture in A-Sub. (\#28)

Even I, myself thought at the beginning 'How can we develop a new product here?' If our capability was, let's say, almost zero back then, now, I'm confident to say that we are almost on par with staff at the HQ. (\#29)

At the beginning, there were only two models of very simple, standardized equipment. Now, we cover a full line-up, ranging from semiconductor to electronic equipment. (\#24)

We have nine product line-ups that include CVT, Step AT, and Hybrid. Our parent company has ten line-ups. You see that we cover almost every product that HQ covers. (\#32)

2005-2006 was a turning point. Before then was a time of learning, and afterwards we utilized what we learned with actual customers in Korea. After we secured businesses with Korean customers such as C-Auto and D-Auto, we started our business with customers in foreign countries such as Taiwan, Indonesia, Thailand, France, and America (\# 30)

Our first customer was C-Elec., and a few years later we won a business with another local major company, D-Elec. Nowadays, we support the Chinese business of our group companies. (\# 28)

Now, A-Sub's former inpatriates are requested by HQ to help their new project. One of my team members, a former inpatriate, went to Japan last year, and he is working in cooperation with other staff at the HQ to develop a next generation equipment. I mean, the technical level is the same now. (\#27) For example, in the case of engineering analysis, approximately 50 engineers in the Japanese headquarters and 53 engineers in B-Sub cooperate as a team, based on the same system. While routine and low-end engineering tasks such as CAD are outsourced to suppliers in Vietnam and India, tasks requiring specialized knowledge such as simulation engineering are undertaken by engineers in Japan and Korea. (\#33)

We now manufacture not only for customers in Korea but also for customers in China. Since the Chinese subsidiary is younger, and does not have enough capability yet, they manufacture only simple standard models. When there are orders of delicate and difficult products, the Chinese subsidiary only takes an order from customers and sends it to us. Then we manufacture and deliver it to the customer and install/service as well. (\#21)

Our staff have lots of business trips to subsidiaries in the U.S., France, and China when a new project starts over there. Because we have more business experience with their local customers such as X-Auto, Y-Auto, and Z-Auto, we support their product development and test processes. (\# 30)

Obviously, the worth of B-Sub in our group [global network] has significantly improved. The HQ's board members visited once or twice a year before, but they come almost every month now. This means they are paying attention to us, and we are important in our group. (\#34)

We are self-sufficient now. Even young engineers from Japan come to B-Sub for learning product development for global customers such as X-Auto and Y-Auto. It is now expected that there will be a local president when the current president goes back to Japan. (\#35) 
At the same time, both subsidiaries extended their product range and customer base successfully through involvement with local customers or suppliers, as evidenced by annual sales growth in Figure $1 \mathrm{a}$ and $\mathrm{b}$. One managing director of B-Sub explained the present composition of their customers:

\begin{abstract}
Now, in B-Sub's responsibility, approximately $60-70 \%$ of our job is to support customers in Korea, for example X-Auto or Y-Auto, and $30-40 \%$ of it is for other global customers in China, Malaysia, Taiwan, etc. Customers' requirements vary, so we are more experienced [than the $\mathrm{HQ}$ ] in that sense. (\#29)
\end{abstract}

Next, as a result of such subsidiary capability building, the role and responsibilities of both subsidiaries in the global MNC network evolved significantly. They grew into more capable and reliable partners that could not only deal with their local customers successfully, but also support the HQ and other foreign subsidiaries. As one manager in the strategy planning department of B-Sub's HQ highlighted:

B-Sub is our right arm. Many of B-Sub's engineers are multilingual and have rich experience with various global customers. By contrast, the Japan HQ deals mostly with customers in Japan. We [staff in B-HQ and B-Sub] have distinctive strengths now. (\#40)

\section{Also, one A-Sub director confidently stated:}

Now, the situation is totally different than at the beginning. The purpose and nature of it [inpatriation] has changed. In 2014, we sent eleven engineers, mostly upon request of the Japanese side, because they needed hands of experienced engineers. Also, one of our chief engineers became the director of a manufacturing subsidiary in China last year. We go out now for teaching, not one-way learning [from the HQ] anymore. (\#26)

At the same time, the interviews in A-HQ and B-HQ confirmed the exceptional capabilities and evolutionary roles of both subsidiaries in their respective networks, both of which were developed through inpatriation. Long serving board members of A-HQ and B-HQ highlighted:

The top manager's [of A-Sub] bold decision to send engineers every year to HQ was critical, I think. The speed of A-Sub's growth is at an unprecedented level in our company. [...] Now, A-Sub and we [A-HQ] do several new product development projects together for C-Elec. and D-Elec., the leading global players. Because state-of-the-art products of semiconductors or LCD do not come from Japan anymore, but from Korea, A-Sub's role became more critical for our company. (\#36)
As we globalize our business, we need more subsidiaries that have tight links and frequent interactions with the HQ. Former inpatriates in B-sub are 'immediate assets'. They actively develop B-Sub's local business, support other overseas subsidiaries, and contribute to our global business as a result. In fact, through B-Sub's experience, we got to know that the one-way flow of expatriates from HQ to subsidiaries was not enough. We need talent that knows both sides [HQ and subsidiaries] very well and acts as a long-term bridge, as former inpatriates of B-Sub do. (\#38)

In sum, A-Sub's and B-Sub's experience provide rich evidence that their capability building, and the resultant evolution of their role, is attributable to their strategic and successive use of inpatriation to transfer knowledge from $\mathrm{HQ}$. Of course, we acknowledge that other factors, such as the macro-economic environment, local customers' growth, and parent company support, might also have influenced this evolution. However, based on our data, we would argue that A-Sub and B-Sub were in a position to fully respond to and seize market opportunities because, through inpatriation, they had developed the capability to draw on the HQ's technological knowledge and synthesize it with local customer needs.

\section{DISCUSSION}

Based on the constructs and relationships emerging from our study, we were able to derive a theoretical model (Figure 2). This model illuminates the process and consequences of inpatriation, showing how it functions in the short and long term and, in turn, how it benefits the entire subsidiary. Specifically, the model outlines a process through which inpatriates bridge $\mathrm{HQ}$ and subsidiaries by close interaction with individuals in both organizations. In this process, a long-term successive practice of inpatriation is indispensable for realizing inpatriates' potential as effective knowledge actors. That is, inpatriates acquired different types of individual tacit knowledge at the HQ through their short-term functions and subsequently converted it into organizational knowledge through their long-term functions, such as building absorptive capacity and maintaining access to information. Eventually this contributed to subsidiary capability building and subsidiary evolution.

\section{Implications for Theory}

Our study bridges and contributes to both the IHRM and the global strategy literatures. Overall, the theoretical model shown in Figure 2 advances 

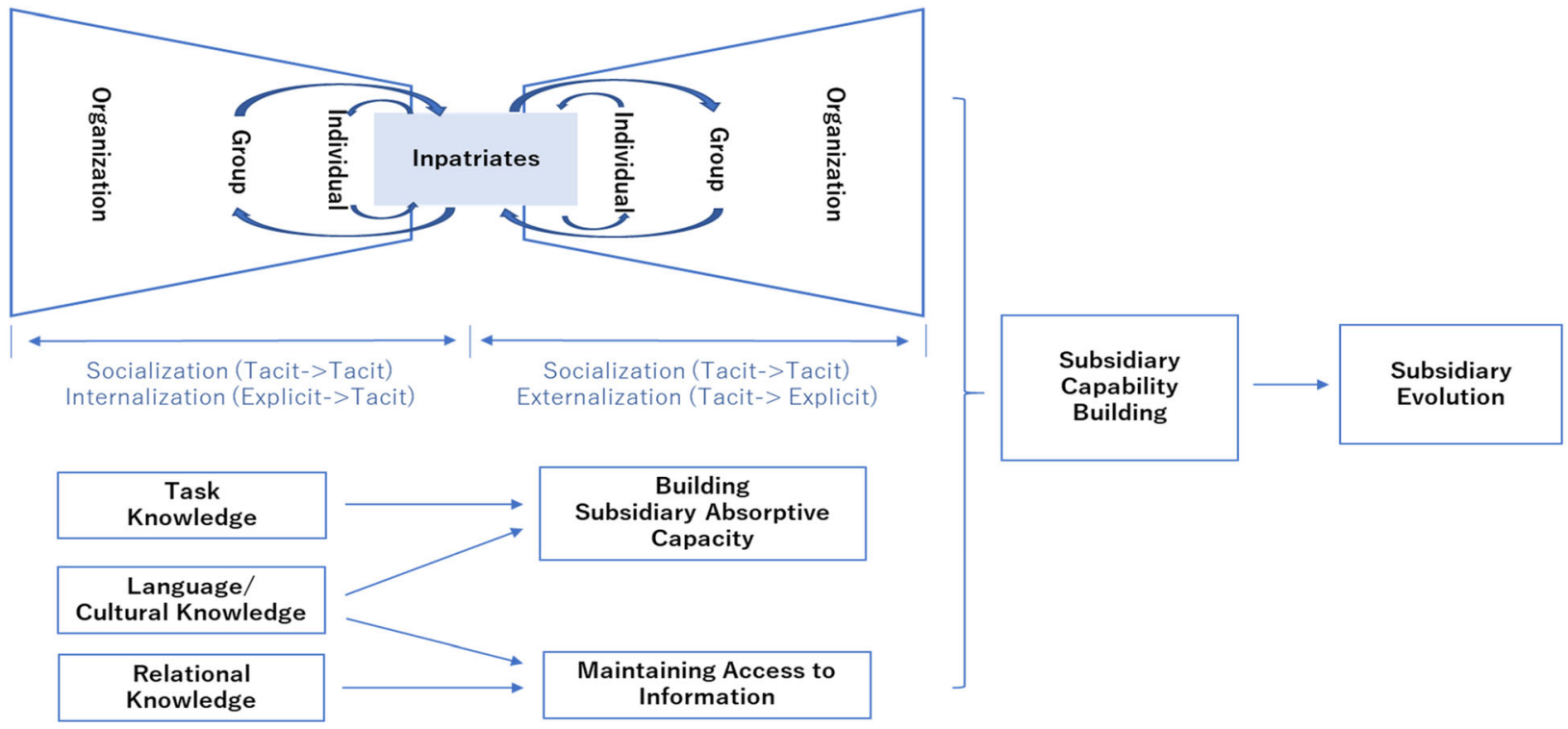

Figure 2 Theoretical model: Successive inpatriation, subsidiary capability building and subsidiary evolution.

our understanding of the process through which inpatriates function as knowledge actors and, in turn, contribute to build subsidiary capability and drive subsidiary evolution. Informed by our data, the model highlights the importance of successive and long-term practices of inpatriation. In the short term, inpatriation enables individual inpatriates to acquire task, language/cultural, and relational knowledge. This individual-level knowledge is then converted into organizational-level knowledge through building absorptive capacity and maintaining access to information in the long term.

The changing number of inpatriates as shown in Figure $1 \mathrm{a}$ and $\mathrm{b}$ indicates such a transition. The two subsidiaries we studied show similar patterns, including a sharp increase in the number of inpatriates in the initial 5-6 years, followed by a sharp decrease in the following 2-3 years, and finally maintaining small numbers of inpatriates thereafter. The initial increase can be understood as an investment of human and time resources to build a knowledge-receptive foundation, so-called absorptive capacity, in a subsidiary (Cohen \& Levinthal, 1990). Once a subsidiary has built a foundation for continuous knowledge transfer from $\mathrm{HQ}$, it can decrease the number of inpatriates, leaving a narrower channel of staff mobility towards the HQ. Minbaeva, Pedersen, Björkman, Fey and Park (2003) pointed out that our knowledge of how HRM influences the absorptive capacity of a subsidiary, and, in turn, internal MNC knowledge transfer is still very rudimentary. Our theoretical model provides useful insights to understand the link between HRM and knowledge-related performance outcomes that have thus far remained a black box (Minbaeva, 2013; Minbaeva, Pedersen, Björkman, \& Fey, 2014).

More specifically, our theoretical model advances research in the following three distinct areas that emphasize different stages of this model. First, our study extends organizational knowledge creation theory (Nonaka, 1994) to an MNC context. By empirically showing the knowledge conversion process in the HQ and subsidiary context, our study provides insights into how knowledge is transferred and created through individuals in the MNC network. As elaborated in the previous section and shown in Figure 2, inpatriates experience 'socialization' through close individual interactions with HQ staff, which is the process of converting new tacit knowledge through shared experiences and mutual understanding. At the same time, inpatriates go through 'internalization' which is the process of embodying explicit knowledge into tacit knowledge through acquiring task knowledge, language/cultural knowledge, and relational knowledge in the HQ. Through the socialization and internalization, inpatriates accumulate tacit knowledge at the individual level, then set off a new spiral of knowledge creation when they share 
it with subsidiary staff upon their return through direct individual interactions, which constitutes another round of socialization. In addition, inpatriates realize 'externalization', which is the process of articulating tacit knowledge into explicit knowledge, in the form of new product development or manufacturing quality improvement in the local market context. The socialization and externalization are facilitated through close and repeated interactions via team processes, which result in enhanced subsidiary absorptive capacity. Figure 2 specifically highlights that the knowledge conversion is embedded in a social process and context at both HQ and subsidiaries. Our study thus suggests that the SECI model provides a useful basis to further investigate the dynamic link between IHRM and knowledge-related performance outcomes in the MNC context.

In addition, applying organizational knowledge creation theory to our study advances our understanding of why inpatriation has been found to be a superior way to transfer knowledge to subsidiaries (Duvivier et al., 2019; Harzing et al., 2016). Existing studies surmised that 'subsidiary employees are likely to value knowledge derived from the MNC's HQ' (Reiche, 2012: 1058). While this helps explain how inpatriates' knowledge is socially justified in subsidiaries, it has remained unclear why inpatriates might be more useful knowledge actors in subsidiaries than expatriates. Our findings regarding the knowledge conversion process in subsidiaries provide a complementary explanation. Inpatriates transfer knowledge assets of the HQ to the subsidiary and then create meaning of the knowledge asset in a specific local market context ('ba'), which results in enhanced subsidiary performance. As knowledge creation is a dynamic human process, the key of ' $\mathrm{ba}$ ' is individual interaction. Because inpatriates share the same background with other subsidiary members in terms of culture, language and business context, their interactions with team members are likely to be more extensive, effective and in-depth when compared to foreign expatriates. Additionally, inpatriates tend to be lower or middle managers who sustain a wider range of interactions with subsidiary members, while expatriates are typically higher-level managers who tend to have more limited interactions with them. Therefore, inpatriates' close interactions with subsidiary members and the resultant knowledge transfer could enable a 'bottom-up' upgrading of subsidiary capabilities. This is also emphasized in organizational knowledge creation theory. Indeed, Nonaka et al. (2000: 22) argue that "in knowledge creation, 'distributed leadership' as seen in 'middle-up-down' management is the key, as it cannot be 'managed' with traditional topdown leadership." In an MNC and global staffing context, if top-down leadership denotes traditional expatriates, inpatriates are a good example of middle-up-down managers. Inpatriates synthesize the tacit knowledge of both subsidiary staff and HQ staff, make it explicit, and incorporate it into new technologies and products in a specific subsidiary context.

Second, our study has revealed the specific value of inpatriates as knowledge agents. Existing studies on inpatriation provide useful insights into the various roles and functions of inpatriates, such as increasing diversity and providing a multicultural perspective to HQ (Harvey \& Buckley, 1997; Harvey et al., 1999), sharing corporate cultural values throughout the MNC (Froese et al., 2016; Gertsen \& Soderberg, 2012; Sekiguchi et al., 2019), and transferring knowledge between $\mathrm{HQ}$ and subsidiaries (Duvivier et al., 2019; Harzing et al., 2016; Reiche, 2011). However, our knowledge about the specific value that these inpatriate roles contribute to the HQ and subsidiary organizations has been limited, because research examining inpatriation over time has remained scarce to date. Without demonstrating its lasting impact on organizational performance, inpatriation is likely to continue to be considered a negligible IHRM practice. Our study has therefore taken one step forward in addressing this research gap by clarifying how inpatriation can contribute to subsidiary capability building and subsidiary evolution.

Third, our study also contributes to the global strategy literature by suggesting successive inpatriation as a practical and effective process of intraMNC knowledge transfer, through which a subsidiary can build its capabilities and evolve its role in the differentiated MNC network (Bartlett \& Ghoshal, 1986; Ghoshal \& Nohria, 1997). Subsidiaries are embedded both in their external local network and the internal MNC network (e.g., Ciabuschi, Holm, \& Martin, 2014; Ryan, Giblin, Andersson, \& Clancy, 2018), thereby enabling its access to varied knowledge (Bartlett \& Ghoshal, 1989). In studies concerning vertical knowledge transfer between HQ and subsidiaries, most 
attention has been devoted to understanding determinants of knowledge transfer at one end of the transfer process, either for the source or the recipient (Michailova \& Mustaffa, 2012). However, the process through which these can be developed and ultimately drive knowledge transfer has remained unexplored to date. By explaining how successive inpatriation contributes to positive change in a subsidiary, we provide a deeper and more nuanced understanding of the micro-foundations of intraMNC knowledge transfer processes (see Contractor et al., 2019; Foss \& Pedersen, 2019).

Specifically, our study shows how subsidiaries develop and transform themselves from passive recipients of HQ knowledge to active contributors to the wider MNC network, through the knowledge transfer role enacted by inpatriates. In the global strategy literature, it has been widely acknowledged that the traditionally passive role of subsidiaries has shifted to a more active role, expressed as world mandates, global innovators, or centers of excellence (e.g., Birkinshaw \& Hood, 1998; Gupta \& Govindarajan, 2000; O'Brien, Scott, Andersson, Ambos, \& $\mathrm{Fu}, 2019)$. Although a snapshot of subsidiaries in an MNC network can reveal the differentiated roles and capabilities of subsidiaries, it cannot explain how some subsidiaries build stronger capabilities and evolve more successfully than others. Our study contributes to addressing this gap, showing how newly established subsidiaries transform themselves through knowledge transfer by successive inpatriation.

\section{Managerial Implications}

Along with these theoretical contributions, our study has important practical implications as well. First, we recommend MNCs to take into account the strategic use of inpatriation. Our findings provide rich evidence of how inpatriates contribute to knowledge transfer and subsidiary development, which ultimately serve as a source of competitive advantage for the wider MNC. Although global staffing practices have become more varied compared to the past, expatriates still take up the most prominent position. This might not be because expatriates are the most efficient approach to global staffing, but simply because it is an established and well-known practice that other MNCs also use. Expatriates and inpatriates have strengths in different types of knowledge. While expatriates have advantages in accessing HQ-based technological and managerial knowledge, inpatriates can combine HQ-based knowledge with rich knowledge regarding the host country, including its institutional context, business culture, language, customer preferences, etc. Therefore, depending on the nature of the host country and competitive environment, inpatriates might well outperform expatriates in transferring knowledge from HQ to subsidiaries. Our case studies show that inpatriates can take a leading role in bridging HQ and subsidiaries, effectively linking technological knowledge of the HQ and market/customer knowledge of subsidiaries.

Second, our findings provide insights to MNC managers on how to manage inpatriates in order to enhance organizational performance. Specifically, we point to the importance of successive inpatriation and appropriate management of each phase of inpatriation. First, a subsidiary could design a longterm plan of successive inpatriation to build a foundation and channel for knowledge flows with HQ. Sporadic patterns of inpatriation depending on projects only serve as temporary means of knowledge acquisition, without diffusing and extending this knowledge to the whole organization. Second, careful planning is needed not only for selection and training of inpatriates, but also for the management of former inpatriates after their repatriation. This includes encouraging former inpatriates to disseminate their acquired knowledge in the subsidiaries and to maintain access to information. Appointing a former inpatriate as the team leader for a specific project with local customers was a common practice in our case studies. This prompted the former inpatriates to teach their junior team members, and to stay connected with the HQ members to source necessary technological know-how.

Third, our data also suggest that inpatriates would be effective when speedy knowledge transfer to a focal subsidiary is required. When the host market/customer is growing fast and competitive pressure among MNCs and local companies is high, MNCs need to develop their subsidiaries' capabilities in a speedy manner to compete successfully. That is why our seven sample MNCs actively utilize inpatriation in Asian countries. Considering Japanese MNCs' traditionally high dependence on expatriates in their global management, this result reflects the changing nature of their global staffing in response to the changing nature of host 
countries and markets. Our empirical results imply that MNCs need to balance the nature of a host market and its competition with the global staffing composition in order to foster knowledge transfer to the host market.

\section{Limitations and Suggestions for Further Research} Despite its important contributions, our study has a number of limitations that call for future research. First, our findings should be evaluated against the limitations that are inherent in the case study method. Since we somewhat narrowly focused on Japanese MNCs in Korea, our findings should be viewed as exploratory, and we need to be careful in generalizing our findings to inpatriation in MNCs of other contexts. We would argue that our findings, especially the process of inpatriates' knowledge transfer between HQ and subsidiaries, have high potential for generalizability. However, the degree of necessity and effectiveness of inpatriation may depend on specific situations and the nature of home and host countries in three ways. First, geographic, cultural, political and economic proximity between the home and host country should accelerate inpatriates' knowledge transfer process, because it would enhance the speed of inpatriates' learning and facilitate continuous interactions between HQ and subsidiary staff. Second, when an MNC's home market is saturated and shrinking, MNCs might experience the urge to drive growth in foreign markets. MNCs from these countries might thus have a higher need to utilize inpatriation to further stimulate knowledge creation in foreign subsidiaries than MNCs from growing markets. Similar to MNCs from other developed countries, Japanese MNCs constitute a representative case. They have traditionally relied more heavily on expatriate managers from Japan compared to European and US MNCs (Belderbos \& Heijltjes, 2005; Harzing \& Noorderhaven, 2008; Harzing \& Sorge, 2003; Kopp, 1994). These practices were optimal when the firms' core competences or sources of competitive advantage were mostly located in Japan (Sekiguchi et al., 2016). However, given the increasing saturation and shrinking of the domestic market, combined with a growth of international competition with firms from emerging economies such as China, Korea, and Taiwan, Japanese MNCs have increasingly used inpatriation as a supplementary approach. Third, when subsidiaries are located in a volatile host market with rapid market growth and high competitive pressures, the necessity and effectiveness of inpatriation would be higher compared with subsidiaries located in a saturated and less competitive market. In this regard, our sample subsidiaries located in Korea and China exemplified the use of inpatriation in order to develop subsidiary capabilities in a speedy way to seize opportunities in rapidly growing markets. However, as our study is limited to one particular context, future research could adopt a cross-country research design to allow for comparisons among MNCs in diverse contexts. In addition, the pattern or length of inpatriation practices might vary according to the industry, a firm's global strategic orientation, a subsidiary's role, and existing global staffing policies. Although we believe that our theoretical model is able to cover a wide spectrum of inpatriation practices, we would encourage future studies to examine and extend it.

Second, we acknowledge that our retrospective data collection design should ideally be supplemented with other types of data in future studies. Retrospective data are associated with a number of limitations such as lack of recall, distortion, postevent rationalization, or difficulties in determining cause and effect (Golden, 1992; Leonard-Barton, 1990). On the other hand, interviewees' involvement in real-time, repeated or longitudinal studies that deal with ongoing events might also lead to problems such as emotional biases, misattribution, distortion or actual concealment of important facts. Therefore, both kinds of data sources may produce potentially different time-bound 'truths' (Blazejewski, 2011). In our study, the focal events under study (i.e., inpatriation) take significant time to prompt relevant outcomes within an organization (i.e., subsidiary capability building and subsidiary evolution) (Langley, 1999). As such, we believe that retrospective data collection is a suitable research strategy for our purpose. However, to consolidate our findings and extend their generalizability, repeated data collection during an early stage or a more advanced stage of inpatriation would be useful to illuminate inpatriates' real-time activities.

A third relevant topic for future research would be to study how complementary roles of inpatriates and expatriates contribute to intra-MNC knowledge transfer and value creation in subsidiaries. In this paper, we focused on inpatriates' knowledge agency for long-term subsidiary performance. 
However, to better understand how individual mobility allows for the transfer of knowledge to subsidiaries and how it enhances their performance, the inclusion of expatriates in a future study would be beneficial. Important questions to be explored include how different types of international assignees interact, when and how they create synergies, and how their interactions and synergies contribute to subsidiary performance.

\section{CONCLUSION}

In this article, we investigated whether and how knowledge transfer through inpatriation contributes to performance-related outcomes in subsidiaries from the perspective of organizational knowledge creation theory. Based on 18 preliminary interviews in seven Japanese MNCs' HQ and eleven of their subsidiaries in China and Korea, as well as 22 in-depth interviews in two of these Japanese HQs and two of their Korean subsidiaries, we derived a theoretical model illustrating the process through which knowledge transfer through inpatriation facilitates both subsidiary capability building and evolution. We thus argue that successive inpatriation is not merely a staffing method that is complementary or secondary to expatriation, but a key practice in its own right to support subsidiaries' growth and development process.

\section{ACKNOWLEDGEMENTS}

We are deeply grateful for the guidance and constructive comments of Area Editor Mary Teagarden and the three anonymous reviewers. We also thank Helene Tenzer for her valuable feedback on earlier versions of our manuscript. This work was supported by JSPS KAKENHI Grant Numbers JP12926992, JP12808804, JP14445974, and JP20243632.

\section{NOTES}

${ }^{1}$ We investigated 47 Japanese MNCs and conducted 95 interviews in the Japanese HQs and ten Asian countries of the MNCs (China, Cambodia, India, Indonesia, Korea, Malaysia, Singapore, Taiwan, Thailand, Vietnam) between 2012 and 2016, under the research projects of (a) 'Dynamic analysis on market strategy and organizational capability building of Japanese companies in emerging markets' (2012-2013, JSPS KAKENHI Grant Number 12926992), and (b) 'Foreign subsidiaries' capability building in product development function' (2012-2016, JSPS KAKENHI Grant Number $12808804,14445974)$.

\section{REFERENCES}

Adler, P. S., \& Kwon, S.-W. 2002. Social capital: Prospects for a new concept. Academy of Management Review, 27(1): 17-40.

Andersen, P. H., \& Kragh, H. 2011. Beyond the inductive myth: New approach to the role of existing theory in case research. In R. Piekkari, \& C. Welch (Eds.), Rethinking the case study in international business and management research: 146-167. Cheltenham: Edward Elgar Publishing Limited.

Andersson, U. R., Brewster, C. J., Minbaeva, D. B., Narula, R., \& Wood, G. T. 2019. The IB/IHRM interface: Exploring the potential of intersectional theorizing. Journal of World Business, 54(5): $1-8$.

Argote, L. 1999. Organizational learning: Creating, retaining, and transferring knowledge. Norwell, MA: Kluwer.

Asakawa, K. 2001. Organizational tension in international R\&D management: The case of Japanese firms. Research Policy, 30(5): 735-757.

Bartlett, C. A., \& Ghoshal, S. 1986. Tap your subsidiaries for global reach. Harvard Business Review, 64(6): 87-94.

Bartlett, C. A., \& Ghoshal, S. 1989. Managing across borders. The transnational solution. Boston: Harvard Business School Press.

Belderbos, R. A., \& Heijltjes, M. G. 2005. The determinants of expatriate staffing by Japanese multinationals in Asia: Control,

learning and vertical integration. Journal of International Business Studies, 36(3): 341-354.

Berry, H. 2015. Knowledge inheritance in global industries: The impact of parent firm knowledge on the performance of foreign subsidiaries. Academy of Management Journal, 58(5): 1438-1458.

Birkinshaw, J., \& Hood, N. 1998. Multinational subsidiary evolution: Capability and charter change in foreign-owned subsidiary firms. Academy of Management Review, 23(4): 773-795.

Birkinshaw, J., Hood, N., \& Young, S. 2005. Subsidiary entrepreneurship, internal and external competitive forces, and subsidiary performance. International Business Review, 14(2): 227-248.

Blazejewski, S. 2011. When truth is the daughter of time: Longitudinal case studies in international business research. In R. Piekkari, \& C. Welch (Eds.), Rethinking the case study in international business and management research: 251-271. Cheltenham: Edward Elgar Publishing Limited.

Budhwar, P., \& Debrah, Y. A. 2009. Future research on human resource management systems in Asia. Asia Pacific Management Journal, 26(2): 197-218. 
Caligiuri, P., \& Bonache, J. 2016. Evolving and enduring challenges in global mobility. Journal of World Business, 51(1): 127-141.

Cantwell, J., \& Mudambi, R. 2005. MNE competence-creating subsidiary mandates. Strategic Management Journal, 26(12): 1109-1128.

Cerdin, J. L., \& Sharma, K. 2014. Inpatriation as a key component of global talent management. In A. Al Ariss (Ed.), Global talent management: Challenges, strategies, and opportunities: 79-92. Cham: Springer.

Chang, Y., Gong, Y., \& Peng, M. W. 2012. Expatriate knowledge transfer, subsidiary absorptive capacity, and subsidiary performance. Academy of Management Journal, 55(4): 927-948.

Ciabuschi, F., Holm, U., \& Martin, O. M. 2014. Dual embeddedness, influence and performance of innovating subsidiaries in the multinational corporation. International Business Review, 23(5): 897-90.

Cohen, W. M., \& Levinthal, D. A. 1990. Absorptive capacity: A new perspective on learning and innovation. Administrative Science Quarterly, 35(1): 128-152.

Colakoglu, S., \& Caligiuri, P. 2008. Cultural distance, expatriate staffing and subsidiary performance: The case of US subsidiaries of multinational corporations. International Journal of Human Resource Management, 19(6): 223-239.

Collings, D. G. 2014. Integrating global mobility and global talent management: Exploring the challenges and strategic opportunities. Journal of World Business, 49(2): 253-261.

Collings, D. G., \& Isichei, M. 2017. The shifting boundaries of global staffing: Integrating global talent management, alternative forms of international assignments and non-employees into the discussion. The International Journal of Human Resource Management, 29(1): 165-187.

Collings, D. G., McDonnell, A., Gunningle, P., \& Lavelle, J. 2010. Swimming against the tide: Outward staffing flows from multinational subsidiaries. Human Resource Management, 49(4): 575-598.

Collinson, S., \& Rugman, A. M. 2008. The regional nature of Japanese multinational business. Journal of International Business Studies, 39(2): 215-230.

Contractor, F., Foss, N. J., Kundu, S., \& Lahiri, S. 2019. Viewing global strategy through a microfoundations lens. Global Strategy Journal, 9(1): 3-18.

De Cieri, H., \& Dowling, P. J. 2012. Strategic human resource management in multinational enterprises: Developments and directions. In G. K. Stahl, I. Björkman, \& S. Morris (Eds.), Handbook of research in international human resource management: 15-35 (2nd ed.). Cheltenham: Edward Elgar Publishing Limited.

Duvivier, F., Peeters, C., \& Harzing, A. W. 2019. Not all international assignments are created equal: HQ-subsidiary knowledge transfer patterns across types of assignments and types of knowledge. Journal of World Business, 54(3): 81-190.

Fang, Y., Jiang, G. L., Makino, S., \& Beamish, P. W. 2010. Multinational firm knowledge, use of expatriates, and foreign subsidiary performance. Journal of Management Studies, 47(1): 27-54.

Foss, N. I., \& Pedersen, T. 2019. Microfoundations in international management research: The case of knowledge sharing in multinational corporations. Journal of International Business Studies, 50(9): 1594-1621.

Froese, F. J., Kim, K., \& Eng, A. 2016. Language, cultural intelligence, and inpatriate turnover intentions: Leveraging values in multinational corporations through inpatriates. Management International Review, 56(2): 283-301.

Gaur, A. S., Delios, A., \& Singh, K. 2007. Institutional environments, staffing strategies, and subsidiary performance. Journal of Management, 33(4): 611-636.

Gertsen, M. C., \& Soderberg, A. M. 2012. Inpatriation in a globalizing MNC: Knowledge exchange and translation of corporate culture. European Journal of International Management, 6(1): 29-44.

Ghoshal, S., \& Nohria, N. 1997. The differentiated network: Organizing multinational corporations for value creation. San Francisco, CA: lossey-Bass.

Glaser, B., \& Strauss, A. 1967. The discovery of grounded theory: Strategies for qualitative research. Mill Valley, CA: Sociology Press.

Golden, B. R. 1992. The past is the past-or is it? The use of retrospective accounts as indicators of past strategy. Academy of Management Journal, 35(4): 848-860.

Grant, R. M. 1996. Towards a knowledge-based theory of the firm. Strategic Management Journal, 17(S2): 109-122.

Gupta, P. K., \& Govindarajan, V. 2000. Knowledge flows within multinational corporations. Strategic Management Journal, 21(4): 473-496.

Harvey, M. G., \& Buckley, M. R. 1997. Managing inpatriates: Building a global core competency. Journal of World Business, 32(1): 35-52.

Harvey, M. G., \& Miceli, N. 1999. Exploring inpatriate manager issues: An exploratory empirical study. International Journal of Intercultural Relations, 23(3): 339-371.

Harvey, M., Speier, C., \& Novicevic, M. M. 1999. The role of inpatriation in global staffing. The International Journal of Human Resource Management, 10(3): 459-476.

Harzing, A.-W. 2001. Who's in charge? An empirical study of executive staffing practices in foreign subsidiaries. Human Resource Management, 40(2): 139-158.

Harzing, A. W., \& Noorderhaven, N. 2008. Headquarterssubsidiary relationships and the country-of-origin effect. In M. P. Feldman, \& G. D. Santangelo (Eds.), New perspectives in international business research. Progress in international business research: 13-40, vol. 3. Bingley: Emerald Group Publishing Limited.

Harzing, A.-W., Pudelko, M., \& Reiche, B. S. 2016. The bridging role of expatriates and inpatriates in knowledge transfer in multinational corporations. Human Resource Management, 55(4): 679-659.

Harzing, A. W., \& Sorge, A. M. 2003. The relative impact of country-of-origin and universal contingencies on internationalization strategies and corporate control in multinational enterprises: World-wide and European perspectives. Organization Studies, 24(2): 187-214.

Kawai, N., \& Chung, C. 2019. Expatriate utilization, subsidiary knowledge creation and performance: The moderating role of subsidiary strategic context. Journal of World Business, 54(1): 24-36.

Kogut, B., \& Zander, U. 1992. Knowledge of the firm, combinative capabilities, and the replication of technology. Organization Science, 3(3): 383-397.

Kogut, B., \& Zander, U. 1993. Knowledge of the firm and the evolutionary theory of the multinational corporation. Journal of International Business Studies, 24(4): 625-645.

Kopp, R. 1994. International human resource policies and practices in Japanese, European and United States multinationals. Human Resource Management, 33(4): 581-599.

Kuemmerle, W. 1999. The drivers of foreign direct investment into research and development: An empirical investigation. Journal of International Business Studies, 30(1): 1-24.

Langley, A. 1999. Strategies for theorizing from process data. Academy of Management Review, 24(4): 691-710.

Leonard-Barton, D. 1990. A dual methodology for case studies: Synergetic use of longitudinal single site with replicated multiple sites. Organization Science, 1(3): 248-266.

Liu, Y., \& Meyer, K. E. 2020. Boundary spanners, HRM practices, and reverse knowledge transfer: The case of Chinese crossborder acquisitions. Journal of World Business, 55(2): 100958.

Lundvall, B., \& Johnson, B. 1994. The learning economy. Journal of Industry Studies, 1(2): 23-42. 
Luo, Y. 2002. Capability exploitation and building in a foreign market: Implication for multinational enterprise. Organization Science, 13(1): 48-63.

Mason, M. 2010. Sample size and saturation in PhD studies using qualitative interviews. Forum Qualitative Sozialforschung/forum: Qualitative Social Research, 11(3): 1-19.

McNulty, Y. M., \& Brewster, C. 2017. Theorizing the meaning(s) of "expatriate": Establishing boundary conditions for business expatriates. The International Journal of Human Resource Management, 28(1): 27-61.

Meyer, K. E., Li, C., \& Schotter, A. P. J. 2020. Managing the MNE subsidiary: Advancing a multi-level and dynamic research agenda. Journal of International Business Studies, 51(4): 538-576.

Michailova, S., \& Mustaffa, Z. 2012. Subsidiary knowledge flows in multinational corporations: Research accomplishments, gaps and opportunities. Journal of World Business, 47(3): 383-396.

Miles, M. B., Huberman, A. M., \& Saldana, J. 2014. Qualitative data analysis: A methods sourcebook ( 3 rd ed.). Thousand Oaks, CA: Sage.

Miller, C. C., Cardinal, L. B., \& Glick, W. H. 1997. Retrospective reports in organizational research: A reexamination of recent evidence. Academy of Management Journal, 41(1): 189-204.

Minbaeva, C. 2013. Strategic HRM in building micro-foundations of organizational knowledge-based performance. Human Resource Management Review, 23(4): 378-390.

Minbaeva, C., Pedersen, T., Björkman, J., \& Fey, C. F. 2014. A retrospective on: MNC knowledge transfer, subsidiary absorptive capacity, and HRM. Journal of International Business Studies, 45(1): 52-62.

Minbaeva, C., Pedersen, T., Björkman, J., Fey, C. F., \& Park, H. J. 2003. MNC knowledge transfer, subsidiary absorptive capacity, and HRM. Journal of International Business Studies, 34(6): 586-599.

Ministry of Foreign Affairs. 2018. Annual report of statistics on Japanese national overseas. https://www.mofa.go.jp/mofaj/ files/000368753.pdf.

Moeller, M., \& Harvey, M. 2018. Inpatriate career profiles: A historical review and future outlook. In M. Dickmann, V. Suutari, \& O. Wurtz (Eds.), The management of global careers: Exploring the rise of international work: 201-221. Cham, Switzerland: Palgrave Macmillan.

Moeller, M., \& Reiche, B. S. 2017. Inpatriates: A review, synthesis and outlook of two. In Y. McNulty, \& I. Selmer (Eds.), Research handbook of expatriates: 218-240. Cheltenham: Edward Elgar.

Mudambi, R. 2002. Knowledge management in multinational firms. Journal of International Management, 8(1): 1-9.

Nobel, R., \& Birkinshaw, J. 1998. Innovation in multinational corporations: Control and communication patterns in international R\&D operations. Strategic Management Journal, 19(5): 479-496.

Nonaka, I. 1994. A dynamic theory of organizational knowledge creation. Organization Science, 5(1): 14-37.

Nonaka, I., \& Takeuchi, H. 1995. The Knowledge-creating company: How Japanese companies create the dynamics of innovation. New York: Oxford University Press.

Nonaka, I., Toyama, R., \& Konno, N. 2000. SECl, ba and leadership: A unified model of dynamic knowledge creation. Long Range Planning, 33(1): 5-34.

Nonaka, I., von Krogh, G., \& Voelpel, S. 2006. Organizational knowledge creation theory: Evolutionary paths and future advances. Organization Studies, 27(8): 1179-1208.

Noorderhaven, N., \& Harzing, A. W. 2009. Knowledge sharing and social interaction within MNEs. Journal of International Business Studies, 40(5): 719-741.

O'Brien, D., Scott, P. W., Andersson, U., Ambos, T. C., \& Fu, N. 2019. The microfoundations of subsidiary initiatives: How subsidiary manager activities unlock entrepreneurship. Global Strategy Journal, 9(1): 66-91.
Patton, M. Q. 2002. Qualitative research and evaluation methods. Thousand Oaks: Sage.

Peng, M. 2003. Institutional transition and strategic choices. Academy of Management Review, 28(2): 275-296.

Pettigrew, A. M. 1990. Longitudinal field research on change: Theory and practice. Organization Science, 1(3): 267-292.

Piekkari, R., \& Welch, C. 2017. The case study in management research: Beyond the positivist legacy of Eisenhardt and Yin? In C. Cassell, A. L. Cunliffe, \& G. Grandy (Eds.), The SAGE handbook of qualitative business and management research methods: History and traditions: 345-358. London: SAGE.

Reiche, B. S. 2006. The inpatriate experience in multinational corporations: An exploratory case study in Germany. International Journal of Human Resource Management, 17(9): $1572-1590$.

Reiche, B. S. 2011. Knowledge transfer in multinationals: The role of inpatriates' boundary spanning. Human Resource Management, 50(3): 365-389.

Reiche, B. S. 2012. Knowledge benefits of social capital upon repatriation: A longitudinal study of international assignees. Journal of Management Studies, 49(6): 1052-1077.

Reiche, B. S., Lee, Y. T., \& Allen, D. G. 2019. Actors, structure, and processes: A review and conceptualization of global work integrating IB and HRM research. Journal of Management, 45(2): 359-383.

Roth, K., \& Kostova, T. 2003. The use of the multinational corporation as a research context. Journal of Management, 29(6): 883-902.

Ryan, P., Giblin, M., Andersson, U., \& Clancy, J. 2018. Subsidiary knowledge creation in co-evolving context. International Business Review, 27(5): 915-932.

Sarabi, A., Froese, F. J., \& Hamori, M. 2017. Is international assignment experience a ticket to the top of a foreign subsidiary? The moderating effect of subsidiary context. Journal of World Business, 52(5): 680-690.

Sekiguchi, T., Froese, F. J., \& Iguchi, C. 2016. International human resource management of Japanese multinational corporations: Challenges and future direction. Asian Business \&amp; Management, 15(2): 83-109.

Sekiguchi, T., Takeuchi, N., Takeuchi, T., Nakamura, S., \& Ebisuya, A. 2019. How inpatriates internalize corporate values at headquarters: The role of developmental job assignment and psychosocial mentoring. Management International Review, 59(5): 825-853.

Soulsby, A., \& Clark, E. 2011. Theorizing process through punctuated longitudinal case study research. In R. Piekkari, \& C. Welch (Eds.), Rethinking the case study in international business and management research: 277-297. Cheltenham: Edward Elgar Publishing Limited.

Strauss, A., \& Corbin, J. 1998. Basics of qualitative research: Techniques and procedures for developing grounded theory. Thousand Oaks, CA: Sage Publications Inc.

Strutzenberger, A., \& Ambos, T. C. 2014. Unravelling the subsidiary initiative process: A multilevel approach. International Journal of Management Reviews, 16(3): 314-339.

Szulanski, G. 1996. Exploring internal stickiness: Impediments to the transfer of best practices within the firm. Strategic Management Journal, 17(S2): 27-43.

Teece, D., Pisano, G., \& Shuen, A. 1997. Dynamic capabilities and strategic management. Strategic Management Journal, 18(7): 509-534.

Tippmann, E., Scott, P. S., \& Mangematin, V. 2014. Subsidiary managers' knowledge mobilizations: Unpacking emergent knowledge flows. Journal of World Business, 49(3): 431-443.

Tran, Y., Mahnke, V., \& Ambos, B. 2010. The effect of quantity, quality and timing of headquarter-initiated knowledge flows on subsidiary performance. Management International Review, 53(4): 493-511.

Tsai, W., \& Ghoshal, S. 1998. Social capital and value creation: The role of intrafirm networks. Academy of Management Journal, 41(4): 464-476. 
Varma, A., \& Budhwar, P. 2013. Managing human resources in Asia-Pacific (2nd ed.). Abingdon: Routledge.

Wang, S., Tong, T. W., Chen, G., \& Kim, H. 2009. Expatriate utilization and foreign direct investment performance: The mediating role of knowledge transfer. Journal of Management, 35(5): 1181-1206.

Welch, C., \& Piekkari, R. 2006. Crossing language boundaries: Qualitative interviewing in international business. Management International Review, 46(4): 417-437.

Yin, R. K. 2003. Case study research: Design and methods (3rd ed.). Thousand Oaks, CA: Sage.

\section{ABOUT THE AUTHORS}

Heejin Kim (PhD University of Tokyo) is an Associate Professor of International Business at Tohoku University in Sendai, Japan. Her research interests include international HRM, knowledge transfer, and language management of Asian MNCs. She also has interest in qualitative method, hoping to bridge Japanese style field work to international academia.

B. Sebastian Reiche (PhD University of Melbourne) is a Professor of People Management at IESE Business School in Barcelona, Spain. His research focuses on the forms, prerequisites and consequences of global work, international HRM, global leadership, and knowledge transfer. He is associate editor of Human Resource Management Journal, co-editor of Advances in Global Leadership, and regularly blogs on topics related to expatriation and global work (http://blog.iese.edu/expatriatus).
Anne-Wil Harzing (PhD University of Bradford) is a Professor of International Management at Middlesex University, London, and visiting professor at Tilburg University. Her research interests include international HRM, HQ-subsidiary relationships, and the role of language in international business. In addition to her substantive research areas, AnneWil also has a keen interest in issues relating to journal quality and research performance metrics as well as diversity and inclusion in academia (https:// harzing.com).

Open Access This article is licensed under a Creative Commons Attribution 4.0 International License, which permits use, sharing, adaptation, distribution and reproduction in any medium or format, as long as you give appropriate credit to the original author(s) and the source, provide a link to the Creative Commons licence, and indicate if changes were made. The images or other third party material in this article are included in the article's Creative Commons licence, unless indicated otherwise in a credit line to the material. If material is not included in the article's Creative Commons licence and your intended use is not permitted by statutory regulation or exceeds the permitted use, you will need to obtain permission directly from the copyright holder. To view a copy of this licence, visit http://creativecommons.org/licenses/by/4.0/.

Publisher's Note Springer Nature remains neutral with regard to jurisdictional claims in published maps and institutional affiliations.

Accepted by Mary Teagarden, Area Editor, 15 November 2021. This article has been with the authors for two revisions. 